\title{
Evaluating a tylosin dosage regimen for treatment of Staphylococcus delphini infection in mink (Neovison vison): a pharmacokinetic-pharmacodynamic approach
}

\author{
Amir Atabak Ronaghinia ${ }^{1,4^{*}} \mathbb{0}$, Julie Melsted Birch ${ }^{2,4}$, Henrik Lauritz Frandsen ${ }^{3}$, Pierre-Louis Toutain ${ }^{5,6}$, \\ Peter Damborg ${ }^{1}$ and Tina Struve ${ }^{4}$
}

\begin{abstract}
Staphylococcus delphini is one of the most common pathogens isolated from mink infections, especially dermatitis. Tylosin (TYL) is used frequently against these infections, although no evidence-based treatment regimen exists. This study aimed to explore the dosage of TYL for infections caused by $S$. delphini in mink. Two animal experiments with a total of 12 minks were conducted to study the serum pharmacokinetic (PK) characteristics of TYL in mink after $10 \mathrm{mg} /$ $\mathrm{kg}$ IV and oral dosing, respectively. The concentration of TYL in serum samples collected before and eight times during $24 \mathrm{~h}$ after TYL administration was quantitated with liquid chromatography quadrupole time-of-flight mass spectrometry, and the TYL disposition was analyzed using non-linear mixed effect analysis. The pharmacodynamics (PD) of TYL against $S$. delphini were studied using semi-mechanistic modeling of in vitro time-kill experiments. PKPD modeling and simulation were done to establish the PKPD index and dosage regimen. The disposition of TYL was described by a two-compartmental model. The area under the free concentration-time curve of TYL over the minimum inhibitory concentration of S. delphini (fAUC/MIC) was determined as PKPD index with breakpoints of 48.9 and $98.7 \mathrm{~h}$ for bacteriostatic and bactericidal effect, respectively. The calculated daily oral dose of TYL was $2378 \mathrm{mg} / \mathrm{kg}$, which is 238 -fold higher than the currently used TYL oral dosage regimen in mink (10 mg/kg). Accordingly, sufficient TYL concentrations are impossible to achieve in mink plasma, and use of this drug for extra-intestinal infections in this animal species must be discouraged.
\end{abstract}

\section{Introduction}

Staphylococcus delphini is one of the most common bacterial pathogens in mink. As part of the mink mucosal and integumentary microbiota, this is an opportunistic pathogen that may infect different organs, especially skin [1]. For example, pododermatitis (footpad infection) is a common manifestation of this agent causing discomfort, deterioration of fur quality and lower breeding

*Correspondence: amiratabak@sund.ku.dk

${ }^{1}$ Department of Veterinary and Animal Sciences, University of Copenhagen, Stigbøjlen 4, 1870 Frederiksberg C, Denmark

Full list of author information is available at the end of the article rates in mink farms $[2,3]$. Tylosin (TYL) is a veterinary macrolide often used empirically for skin infections in mink despite the absence of an evidence-based treatment regimen. TYL inhibits bacterial protein synthesis and is active against Gram-positive and to a lesser extent Gramnegative bacteria [4]. To the authors' knowledge, there are no pharmacokinetic (PK) or pharmacodynamic (PD) data available for this drug in mink. Therefore, following the European cascade principle [5], the currently used daily oral dosage (typically $10 \mathrm{mg} / \mathrm{kg}$ ) has been adapted from that used in other domestic species, i.e. pig and cattle. The objectives of this study were to (i) investigate PK parameters of TYL in mink after intravenous (IV) and 
oral (PO) administration, (ii) characterize PD parameters of TYL against $S$. delphini, (iii) predict a target value for the TYL PKPD index in mink [6], and (iv) use the obtained data to establish a TYL dosage regimen in mink.

\section{Materials and methods}

\section{Animal experiments}

PK characteristics of TYL after IV and oral administration were investigated in two animal experiments with a total of 12 healthy brown male minks (Neovison vison) purchased from a commercial farm. In the first animal experiment, drug disposition after IV administration was studied in six minks. Each animal was subjected to cephalic IV injection of $10 \mathrm{mg} / \mathrm{kg}$ TYL (tylosin $20 \%$, Tylan ${ }^{\circledR}$ Vet., Elanco Animal Health, Herlev, Denmark), and paired blood samples were collected under anesthesia (see "Blood sampling" section) just before and eight times after antibiotic administration (15, 30, 60 and $120 \mathrm{~min}$, and 6, 10, 15 and $24 \mathrm{~h}$ ) from a cephalic vein and from nails. In the second animal experiment, TYL disposition following oral administration of $10 \mathrm{mg} /$ kg TYL (tylosin phosphate 10\%, Tylan ${ }^{\circledR}$ Vet., Elanco Animal Health, Herlev, Denmark) mixed into 135-150 g feed $(0.2 \mathrm{~g} / \mathrm{kg})$ was explored in six minks. In order to ensure rapid consumption of the feed mix, minks had been fasted for $18 \mathrm{~h}$ prior to medication. Blood samples were collected before and eight times after antibiotic administration (30,60, $120 \mathrm{~min}$ and 6,10,15, 24 and $48 \mathrm{~h}$ ) by nail clipping. Prior to both experiments, minks had been acclimatized for 7-10 days with access to ad libitum water and 250-300 g commercial feed per day in standard commercial cages ( $1^{\text {st }}$ experiment) and in metabolic cages ( $2^{\text {nd }}$ experiment), the latter of which differed by having a feed bowl but no nest attached. Following the Danish order BEK nr 856 of 27.06.2013 $₫$ 1, each cage was equipped with a water bottle, a plastic shelf and a plastic tube as enrichment. After obtaining all blood samples, minks from the IV experiment were euthanized by intracardiac injection of pentobarbital sodium (Euthasol $^{\circledR}$, Virbac Danmark, Kolding, Denmark) while under inhalation anesthesia. Minks from the PO experiment were euthanized by carbon dioxide inhalation following intramuscular injection of ketamine (Ketaminol ${ }^{\circledR}$, MSD Animal Health, Copenhagen, Denmark) and xylazin (Rompun ${ }^{\circledR}$, Bayer, Copenhagen, Denmark).

\section{Anesthesia and analgesia}

In the first animal experiment, IV administration of TYL and the initial five blood samplings were conducted during one continuous up to $3 \mathrm{~h}$ period of inhalation anesthesia using sevoflurane (Sevoflo ${ }^{\circledR}$, Orion Pharma, Copenhagen, Denmark) [7]. Each of the subsequent blood samples were collected during a short period of sevoflurane anesthesia (15-35 min). Anesthesia was induced in an induction chamber with $8 \%$ sevoflurane for 3-5 min after 8-10 min of pre-oxygenation ( $~ 90 \%$ $\left.\mathrm{O}_{2}\right)$. For maintenance, sevoflurane $(2.5-5 \%$, depending on monitored vital signs) was administered through a laryngeal mask (V-gel ${ }^{\circledR}$, Docsinnovent, London, UK). Heart rate, respiration rate, body temperature, noninvasive blood pressure, $\mathrm{O}_{2}$ saturation, hemoglobin in arterial blood, and end tidal $\mathrm{CO}_{2}$ concentration were recorded every 15 min during anesthesia using pulse oximetry and a multifunction anesthesia monitor (Datex Ohmeda, WI, USA). Anesthesia was not applied in the second experiment, as all blood samples were collected from the nails of entrapped awake mink. As an analgesic, $0.2 \mathrm{mg} / \mathrm{kg}$ meloxicam (Metacam, Boehringer Ingelheim International, Germany) was administered subcutaneously immediately before the first blood sampling in both experiments. After nail clipping, ferric chloride hexahydrate (50\%) (Sigma-Aldrich, MO, USA) was applied topically for hemostasis.

\section{Blood sampling}

Blood samples (500-800 $\mu \mathrm{L})$ were collected in capillary tubes (KABE LABORTECHNIK, Elsenroth, Germany) containing a coagulation inducer and a separating gel. After $10 \mathrm{~min}$ at room temperature, to induce clot formation, tubes were centrifuged at $1000 \mathrm{~g}$ for $10 \mathrm{~min}$ followed by storage of the supernatant $(>150 \mu \mathrm{L}$ serum $)$ at $-80{ }^{\circ} \mathrm{C}$ until further analysis.

\section{Serum protein binding rate of TYL}

The binding of TYL to plasma proteins was quantified by an in vitro ultrafiltration method [8]. Prior to the study, fifty $\mathrm{mL}$ pooled serum from 10 different minks in a commercial farm had been collected during pelting by heart puncture immediately after $\mathrm{CO}_{2}$-mediated euthanasia. TYL (Merck, Darmstadt, Germany) was added to thawed serum samples at concentrations of 5,50 and $500 \mu \mathrm{g} / \mathrm{mL}$. As a negative control, TYL was added to PBS. The sera were incubated at $38{ }^{\circ} \mathrm{C}$ for $60 \mathrm{~min}$ to mimic the body temperature of mink. Samples were then filtered using $30 \mathrm{kDa}$ filter tubes (Amicon ${ }^{\circledR}$ Ultra-2, $30 \mathrm{kDa}$; Merck Millipore) with $4000 \mathrm{~g}$ centrifugation for $20 \mathrm{~min}$ at room temperature. Filtered aliquots were stored at $-80^{\circ} \mathrm{C}$ until further analysis. All experiments were conducted in triplicate. To remove glycerin residues from tubes before the experiment, they were washed once with $0.5 \mathrm{~mL}$ of $0.1 \mathrm{M}$ $\mathrm{NaOH}$, rinsed twice with $1.0 \mathrm{~mL}$ PBS, and centrifuged at $7000 \mathrm{~g}$ for $20 \mathrm{~min}$ after each rinse/wash. After quantification of TYL in each sample, a linear regression curve was used to fit the mean value of each concentration. 


\section{Quantification of TYL in samples}

A liquid chromatography (LC) method with quadrupole time of flight mass spectrometry detection (QTOF-MS) was used for measuring the concentration of TYL in serum and PBS samples from the animal experiments and the serum protein binding assay. The detailed procedure is presented in Additional file 1. In brief, matrix-matched calibration samples were prepared in blank serum at seven different concentrations in the range of 4-500 $\mathrm{ng} /$ $\mathrm{mL}$. The standard calibration curves were analyzed at the beginning, after each 20 samples and at the end of the sequence. Extracted ion chromatograms of $\mathrm{m} / \mathrm{z} 916.5264$ $( \pm 0.005)$ were constructed and integrated. No interfering peaks were observed at the retention times of the antimicrobials. Serum concentrations were calculated based on linear calibration curves constructed using $1 / \mathrm{x}$ weighing. As all samples were analyzed in one sequence, the inter-day precision is not relevant, and the intra-day precision (CV\%) for samples was $<10 \%$. The lower limit of quantification (LLOQ) was $30 \mathrm{ng} / \mathrm{mL}$ for TYL. Any data lower than the LLOQ were flagged as Below Quantification Limit (BQL) for data analysis.

\section{In vitro antimicrobial growth (time-kill) experiment}

Time-kill experiments were done using two wild-type clinical S. delphini isolates (16-12727-1, 16-124033) of mink origin after measuring their TYL MIC by broth microdilution according to the Clinical Laboratory Standards Institute [9]. Three to five single colonies from fresh Mueller Hinton agar (MHA) plates were incubated for $2 \mathrm{~h}$ in $5 \mathrm{~mL}$ Mueller Hinton broth (MHB) at $37{ }^{\circ} \mathrm{C}$ with shaking $(150 \mathrm{rpm})$ to reach exponential growth phase. After incubation, bacterial concentration was adjusted to $\sim 10^{8} \mathrm{CFU} / \mathrm{mL}$, and $10 \mu \mathrm{L}$ of this aliquot was inoculated in $2 \mathrm{~mL}$ tubes containing $1 \mathrm{~mL}$ of $\mathrm{MHB}$ supplemented with TYL, followed by incubation at $37^{\circ} \mathrm{C}$ with gentle shaking $(150 \mathrm{rpm})$. The TYL concentrations used in time-kill assays corresponded to 8, 4, 2, 1, 0.5 and 0.25 -fold the MIC values of the two $S$. delphini isolates used for the experiment. Twenty $\mu \mathrm{L}$ aliquots removed at times $0,1,2,4,8$ and $24 \mathrm{~h}$ post-inoculation were tenfold serially diluted in saline followed by plating $4 \times 10 \mu \mathrm{L}$ of each dilution on MHA plates in duplicate for determination of viable counts upon overnight incubation at $37^{\circ} \mathrm{C}$. The LLOQ for the bacterial count was $200 \mathrm{CFU} / \mathrm{mL}$, and data lower than this limit were flagged as BQL for data analysis. The average of viable colony counts was used for analysis.

\section{PD modeling of in vitro antimicrobial growth curves}

A previously described semi-mechanistic model (Figure 1) was used for PD modeling of time-kill data [10].

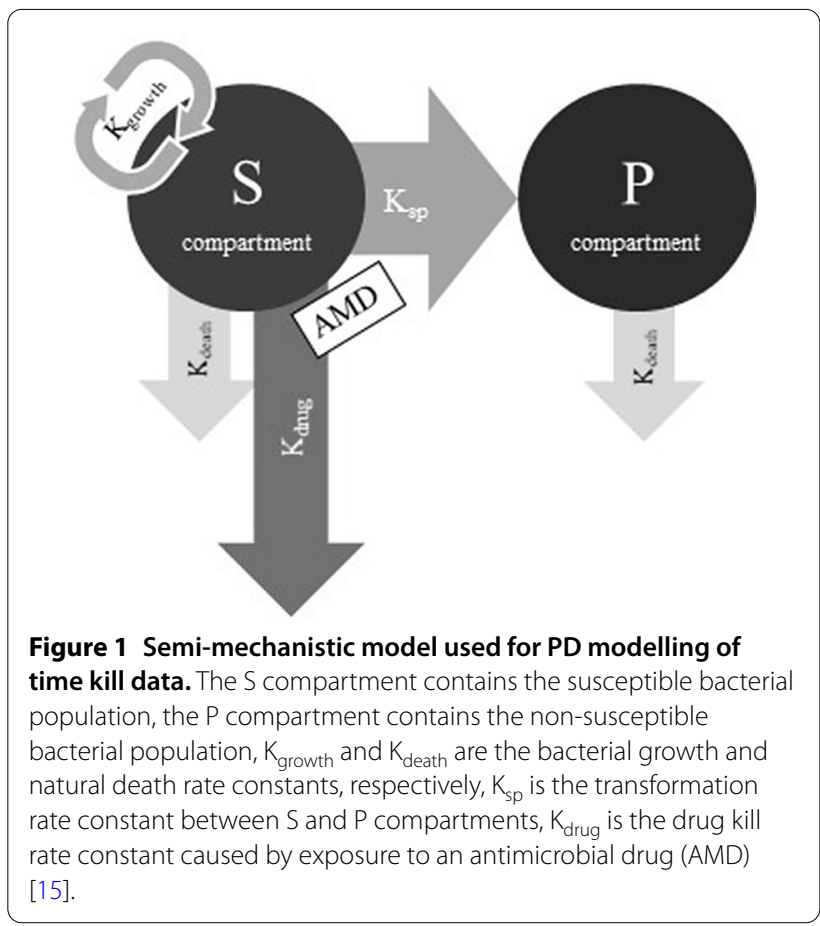

In summary, the model consists of an $\mathrm{S}$ and a $\mathrm{P}$ compartment containing a susceptible and a non-susceptible bacterial population, respectively. The bacterial growth in $\mathrm{S}$ (1) is assumed to be regulated by the natural growth rate, the natural death rate and the kill rate of an antimicrobial drug.

$$
d S / d t=K_{\text {growth }} \times S-\left(K_{\text {death }}+K_{\text {drug }}\right) \times S-K_{S P} \times S
$$

where $\mathrm{S}(\mathrm{CFU} / \mathrm{mL})$ is bacterial concentration in the $\mathrm{S}$ compartment, $t(h)$ is time, and $K_{\text {growth }}, K_{\text {death }}$ and $K_{\text {drug }}$ $(1 / \mathrm{h})$ are rate constants of bacterial growth, bacterial natural death, and bacterial kill by TYL, respectively. $\mathrm{K}_{\mathrm{SP}}(1 / \mathrm{h})$ is a rate constant describing the rate of transfer from the $\mathrm{S}$ to the $\mathrm{P}$ compartment. $\mathrm{K}_{\mathrm{SP}}$ is a linear function of total bacterial concentration $(\mathrm{S}+\mathrm{P})$ in the system (2).

$$
K_{S P}=\frac{\left(k_{\text {growth }}-K_{\text {death }}\right)}{B_{\max }} \times(S+P)
$$

where $B_{\max }(\mathrm{CFU} / \mathrm{mL})$ is the highest achievable bacterial concentration in the system. It is assumed that the bacterial population in the $\mathrm{P}$ compartment has no growth, is non-susceptible to TYL, and has the same natural death rate as in the $\mathrm{S}$ compartment (3).

$$
d P / d t=K_{S P} \times S-K_{\text {death }} \times P
$$


The effect of TYL is assumed to follow a non-linear function that depends on the concentration in the system and is described by an $\mathrm{E}_{\max }$ sigmoid model (4).

$$
K_{D R U G(t)}=\frac{E \max \times C(t)^{\gamma}}{E C_{50}^{\gamma}+C(t)^{\gamma}}
$$

where $E_{\max }(1 / h)$ is maximum bacterial kill by TYL representing drug efficacy, $\mathrm{EC}_{50}(\mathrm{mg} / \mathrm{L})$ is the concentration of TYL that produces half of the maximum effect measuring drug potency, gamma ( $\gamma$-scalar) is a sigmoidicity coefficient expressing the slope of antimicrobial effect curves and presenting drug sensitivity, and $\mathrm{C}(\mathrm{t})$ is the concentration of TYL at time $(\mathrm{t})$.

In addition, the MIC (5) and the minimum bactericidal concentration (MBC) (6) of TYL for S. delphini were estimated directly from the estimated parameters of the model as secondary parameters [11].

$$
\begin{aligned}
& M I C=E C_{50} \times\left(\frac{K_{\text {Growthnet }}-0.26}{\text { Emax }-\left(K_{\text {Growthnet }}-0.26\right)}\right)^{\frac{1}{\text { Gamma }}} \\
& M B C=E C_{50} \times\left(\frac{K_{\text {Growthnet }}+0.288}{\text { Emax }-\left(K_{\text {Growthnet }}+0.288\right)}\right)^{\frac{1}{\text { Gamma }}}
\end{aligned}
$$

where $K_{\text {Growthnet }}$ is the net bacterial growth (i.e. $\left.\mathrm{K}_{\text {Growthnet }}=\mathrm{K}_{\text {Growth }}-\mathrm{K}_{\text {death }}\right)$.

The drug was assumed to possibly undergo an in vitro degradation over the duration of the test, and a parameter reflecting this possible decay $\left(\mathrm{K}_{\mathrm{el}}\right)$ was added to empirically improve the model fit (no experimental data). Since our analysis revealed no evidence of such decay over $24 \mathrm{~h}, \mathrm{~K}_{\mathrm{el}}$ was fixed to 0 . The estimation of parameters were obtained using a non-linear mixed effect analysis (NLME-Phoenix ${ }^{\odot} 8.3$ software package, Certara, NJ, USA), which was based on minimizing an objective function value (OFV) by the population Laplacian engine of Phoenix ${ }^{\circledR}$. Since large variability was expected for $B_{\max }$, the random component was added to this parameter for fitting purposes. BQL data were treated as censored with the M3 method [12]. The parameter mean and precision estimates were obtained by using the bootstrap tool $(n=30$ replicates) in Phoenix 8.3.

\section{PK modeling of in vivo concentration-time data}

A non-linear mixed effect (NLME) analysis of TYL concentration-time data was done using the Phoenix ${ }^{\odot} 8.3$ software package. The objective of this analysis was to estimate the TYL PK parameters and their between subject variability (BSV) in the population after IV and oral dosing. The data obtained following IV and oral administration were analyzed simultaneously and fitted to the one and two-compartmental structural model. Determination of the best model (one- or two-compartmental) was based on visual inspection of plots and Akaike's information criterion (AIC). The variance of parameters across individuals (BSV) was computed based on an exponential model. The variance of parameters has a lognormal distribution and was converted to coefficient of variation $(\mathrm{CV})$ in original scale (7).

$$
\mathrm{CV}(\%)=100 \times \sqrt{\exp \left(\omega^{2}\right)-1}
$$

where omega $\left(\omega^{2}\right)$ is the variance of parameters across individuals.

The random component of the parameter was removed from the model, when shrinkage of random effects toward the means was high $(>0.4)$. The residual error for parameters was modeled using the additive and multiplicative model. As the dose was computed by using plasma clearance, the influence of the sampling site (vein vs. nail) on this PK parameter was tested by comparing the value of the Bayesian Information Criterion (BIC) of the two models with and without including the sampling site as a covariate for the clearance. The censored data (BQL) were handled using the M3 method [12]. A Laplacian engine was used in the estimation process, and the parameters mean and precision were computed using a bootstrap tool $(n=30)$.

\section{Prediction of the TYL PKPD index}

A previously described PKPD model was used in this study [13]. In brief, the in vivo TYL disposition following oral administration was integrated into the in vitro PD model described in Section "PK modeling of in vivo concentration-time data". The PK mono-exponential part of the in vitro model (i.e. $\mathrm{K}_{\mathrm{el}}=0$ ) was replaced by the actual in vivo PK disposition model (see Section "PK modeling of in vivo concentration-time data") to predict the bacteriological effect of TYL. To estimate the PKPD target, simulations of the time development of in silico microbiological load were applied with a bacterial initial load of $5 \times 10^{5} \mathrm{CFU} / \mathrm{mL}$ at four MIC levels $(0.125,0.25,0.5$ and $1 \mathrm{mg} / \mathrm{L}$ ). The wide range of 13 daily doses of TYL corresponding to twofold increases of concentration from $1 \times$ MIC to $2048 \times$ MIC for $S$. delphini, providing 52 paired datasets (i.e. 13 daily doses for each of $4 \mathrm{MIC}$ levels) were simulated for each of two PKPD indices, namely time above the MIC $(f \mathrm{~T}(\%)>\mathrm{MIC})$ and Area Under the Concentration-time curve over the MIC (fAUC/MIC). It was assumed that the efficacy $\left(\mathrm{E}_{\max }\right)$ did not change with $\mathrm{MIC}$ and the difference in MICs was solely dependent on TYL potency $\left(\mathrm{EC}_{50}\right)$. Hence, a scaling factor for the $\mathrm{EC}_{50}$, obtained from the in vitro PD model, was used to convert measured MIC $(0.25 \mathrm{mg} / \mathrm{L})$ to the simulated MIC. 
For the bacteriological effect, $\log _{10}$ transformation of the cumulative area under the curve of the total bacterial concentration over $24 \mathrm{~h}\left(\log _{10} \mathrm{AUC}_{\text {totbact }}\right)$ was used. Bacteriostatic and bactericidal effects were defined as no change and one $\log _{10}$ reduction in the initial inoculum, respectively. The area under the free serum concentration-time curve $\left(f \mathrm{AUC}_{\mathrm{po}, 0-24}\right)$, with $69 \%$ free drug $(f)$, was obtained directly from the PK model (see Section "PK modeling of in vivo concentration-time data"), and percentage of time that serum concentration exceeded MIC within $24 \mathrm{~h}(f \mathrm{~T}(\%)>\mathrm{MIC})$ was computed using the non-compartmental and statistical tools of the Phoenix ${ }^{\odot}$ software package. The 52 datasets of $f \mathrm{~T}(\%)>\mathrm{MIC}$ (independent variable) versus $\mathrm{AUC}_{\text {totbact }}$ (dependent variable) and $f \mathrm{AUC}_{\mathrm{po}, 0-24} / \mathrm{MIC}$ (independent variable) versus AUC totbact (dependent variable) for each bacterial strain were fitted individually for each MIC with an inhibitory sigmoid $\mathrm{I}_{\max }$ model (8).

$$
E=E_{0}-\frac{I_{\max } \times \operatorname{Index}^{\gamma}}{\operatorname{Index}_{50}^{\gamma}+\operatorname{Index} \gamma}
$$

where $E_{0}$ is no effect of TYL (obtained from the control curves for $C(t)=0), I_{\max }$ is extent of the maximal effect, Index ${ }_{50}$ is magnitude of the indices $\left(f \mathrm{AUC} \mathrm{C}_{\mathrm{po}, 0-24 \mathrm{~h}} / \mathrm{MIC}\right.$ or $f \mathrm{~T}(\%)>\mathrm{MIC}$ ) achieving $50 \%$ of the $\mathrm{I}_{\max }$, and $\gamma$ is the sigmoidicity factor reflecting the steepness of the relationship. The maximum observed effect was calculated by subtracting $\mathrm{I}_{\max }$ from $\mathrm{E}_{0}$ (i.e. $\mathrm{E}_{0}-\mathrm{I}_{\max }$ ). Curve fitting was performed in WinNonlin ${ }^{\circledR}$ (Certara, NJ, USA). The coefficients of determination $\left(\mathrm{R}^{2}\right)$, the AIC, and visual inspection of plots were used to select the PKPD index best describing the antimicrobial effect.

\section{TYL dosage prediction}

After obtaining PK and PD parameters, the first dosage regimen was calculated using the following Eq. (9):

$$
\text { Dosage }_{\text {perday }}=\frac{C l_{\text {day }} \times S F \times E C O F F}{F \times f}
$$

where $\mathrm{Cl}_{\text {day }}(\mathrm{L} /$ day $/ \mathrm{kg})$ is the TYL body clearance in $24 \mathrm{~h}$, $\mathrm{SF}$ (scalar) is the scaling factor obtained by dividing the selected PKPD index i.e. $f \mathrm{AUC}_{\mathrm{po}, 0-24 \mathrm{~h}} / \mathrm{MIC}$ by $24 \mathrm{~h}, \mathrm{~F}$ is bioavailability, $f$ is free fraction of drug in serum and ECOFF is the highest MIC for organisms devoid of phenotypically-detectable acquired resistance mechanisms. In this study, we used the recently determined TYL tentative ECOFF (TECOFF) of $2 \mathrm{mg} / \mathrm{L}$ for $S$. delphini [14].

\section{Statistical analysis}

PK and PD parameters from NLME are presented as typical values of the population with corresponding precision as standard errors.

\section{Results}

Serum protein binding rate of TYL

The free fraction of TYL was obtained as the ratio of the slope coefficient b of the spiked serum curve to the control solution curve, multiplied by 100 . According to the results, the mean free fraction of TYL in mink serum was $69 \%$.

\section{Antimicrobial growth (time-kill) experiment}

The MIC of the two S. delphini isolates used in the time kill experiment was $0.25 \mathrm{mg} / \mathrm{L}$. Figure 2 presents the time-kill curves of TYL for these $S$. delphini isolates grown in MHB with two-fold increasing TYL concentrations corresponding to $0.25,0.5,1,2,4$ and $8 \times$ MIC. At 0.25 and $0.5 \times$ MIC, bacterial growth continued until reaching the stationary phase. At the two highest TYL concentrations, a three log reduction in bacterial concentration was observed at $8 \mathrm{~h}$ or at $24 \mathrm{~h}$ post-inoculation depending on the isolate tested (Figure 2).

\section{PD modeling of time-kill experiments}

Plots of observed and individual predicted bacterial population vs. time (latticed by isolate and drug concentrations) are presented in Figure 3, and plots of observed vs. individual model predicted bacterial population are presented in Additional file 2. Estimated primary and secondary parameters for the time-kill model are presented in Table 1 . The degradation rate of TYL $\left(\mathrm{k}_{\mathrm{el}}\right)$ and the bacterial natural death rate in the absence of TYL $\left(k_{\text {death }}\right)$ were fixed to 0 (i.e. no degradation of the drug during $24 \mathrm{~h}$ in test tubes) and $0.171 / \mathrm{h}$ (a classical default value corresponding to a half-life of $4.08 \mathrm{~h}$ [15]), respectively. The maximal bacterial killing rate $\left(\mathrm{E}_{\max }\right)$ of TYL was 0.75 $1 / \mathrm{h}$, yielding a 4.4 fold increase in fixed spontaneous death rate. To achieve half of the maximal killing effect $\left(\mathrm{EC}_{50}\right)$, a TYL concentration of $0.55 \mathrm{mg} / \mathrm{L}$ was required. The MIC and MBC estimated by the model were 0.36 and $1.45 \mathrm{mg} / \mathrm{L}$, respectively. Considering the inherent methodological limitation of MIC measurements (i.e. an MIC may vary two-fold up and down between repeated measurements), the estimated MIC of $0.36 \mathrm{mg} / \mathrm{L}$ predicted by the model was in good agreement with the MIC measured by in vitro broth microdilution $(0.25 \mathrm{mg} / \mathrm{L})$.

\section{The PK parameters and disposition of TYL in mink}

The semi-logarithmic plots of TYL disposition in mink serum after IV and oral administration of $10 \mathrm{mg} / \mathrm{kg}$ body weight are presented in Figure 4 . The dependent variable (DV) i.e. observed serum concentration $(\mu \mathrm{g} / \mathrm{mL})$ vs. individual prediction (IPRED) of concentration $(\mu \mathrm{g} /$ $\mathrm{mL}$ ) plots in arithmetic and logarithmic scale after IV and oral administration are presented in Figure 5. Visual 
A S. delphini isolate 16-12727-1

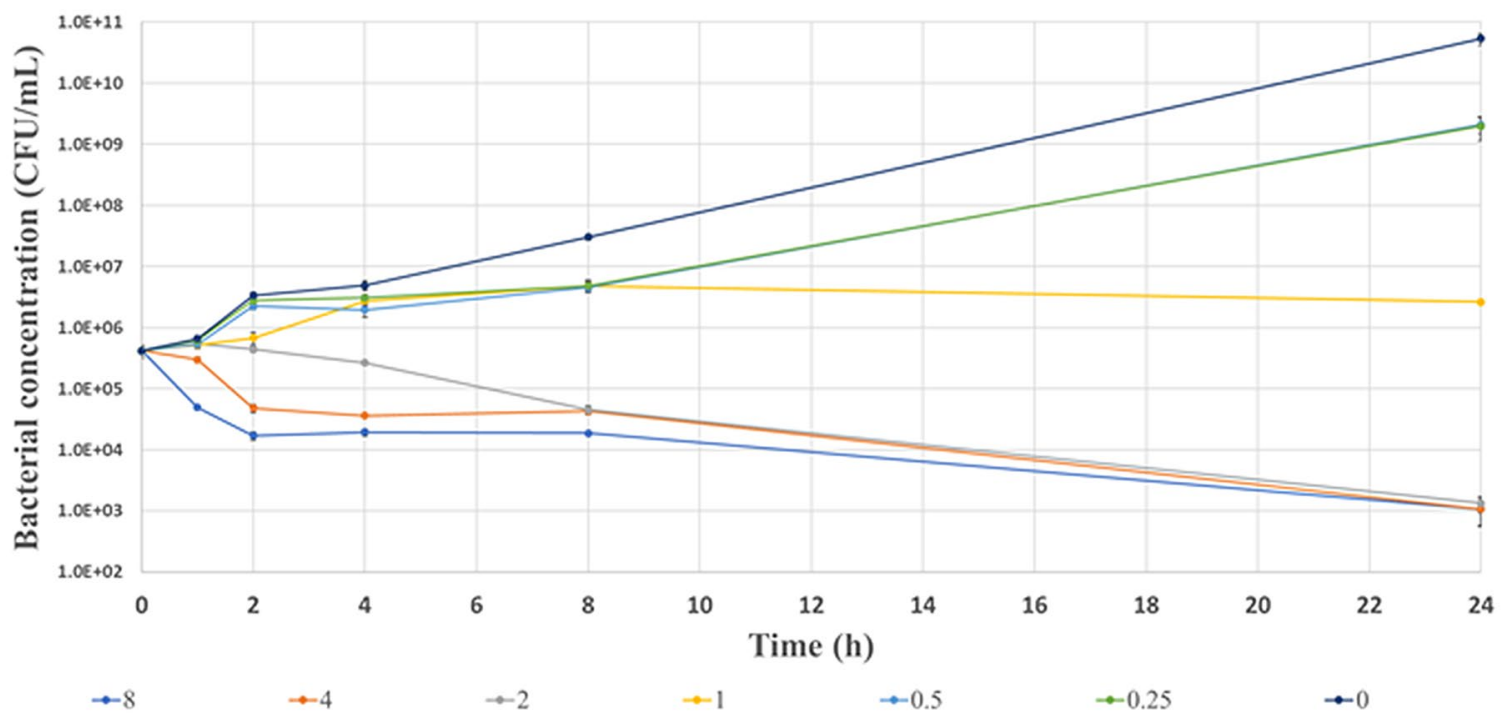

B S. delphini isolate 16-12403-3

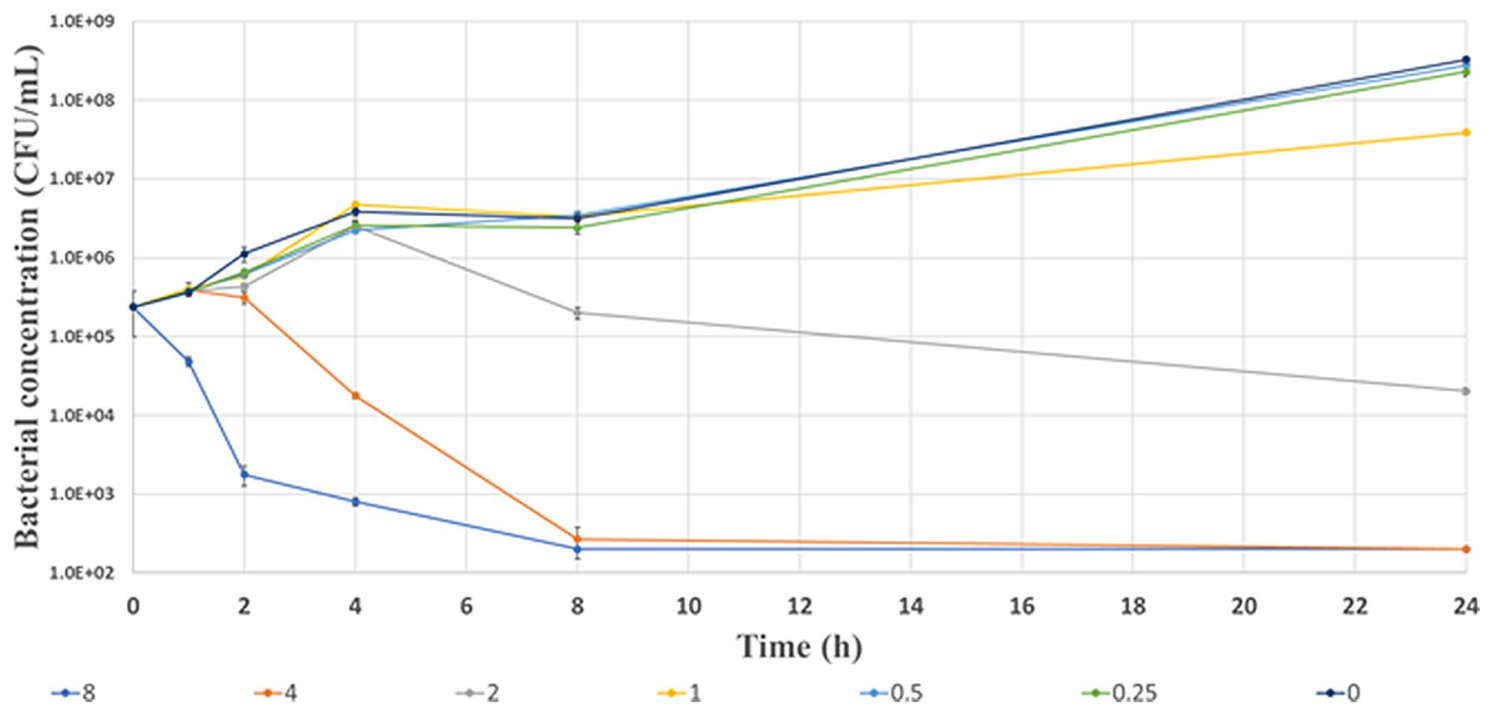

Figure 2 Time kill curves for TYL vs. two isolates of S. delphini (A, B) in MHB over $\mathbf{2 4} \mathbf{h}$. The Y-axis presents the bacterial concentration starting from LLOQ as 200 CFU/mL. The X-axis is the time post-inoculation. The error bar at each time point presents the SD for duplicates. Different colors depict the various TYL concentrations with two-fold increase at each step corresponding to $0.25,0.5,1,2,4$ and $8 \times$ MIC. The MIC for both isolates was $0.25 \mathrm{mg} / \mathrm{L}$. The concentrations higher than $2 \times \mathrm{MIC}$ resulted in bacterial kill in both isolates. In plot $(\mathbf{A})$, the concentrations of 0.5 and $4 \times \mathrm{MIC}$ are masked by 0.25 and $2 \times \mathrm{MIC}$, respectively. In plot (B), the concentrations of 0.25 and $0.5 \times \mathrm{MIC}$ are masked by the control $(0 \times \mathrm{MIC})$.

inspection of the plots shows that the observed and predicted points are close to the line of unity $(x=y)$, except for some data points with high TYL concentrations after oral dosing. The visual predictive check (VPC) plots for different administration modalities are presented in Figure 6. Plots of observed and individual predicted serum concentration vs time after dosing (latticed by individual) are presented in Additional file 3. The NLME-estimated primary and secondary PK parameters following IV and oral administration are presented in Table 2. The bioavailability of TYL was $41 \%$ with the peak plasma concentration $\left(\mathrm{C}_{\max }\right)$ of $0.43 \mathrm{mg} / \mathrm{L}$ observed $1.75 \mathrm{~h}\left(\mathrm{~T}_{\max }\right)$ after oral administration of $10 \mathrm{mg} / \mathrm{kg}$ body weight. The $\mathrm{CL}$ and volumes of distribution $\left(\mathrm{V}_{1}\right.$ and $\left.\mathrm{V}_{2}\right)$ were 3.41 $\mathrm{L} / \mathrm{h} / \mathrm{kg}, 2.24$ and $1.33 \mathrm{~L} / \mathrm{kg}$, respectively, indicating a very high body clearance and extensive distribution of TYL 
(1) Control

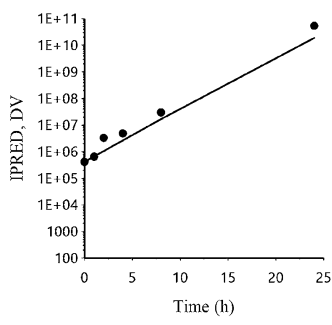

(1) $1 \mathrm{mg} / \mathrm{L}$

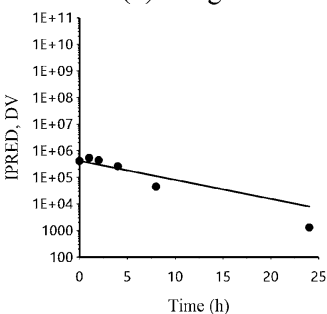

(2) $0.125 \mathrm{mg} / \mathrm{L}$

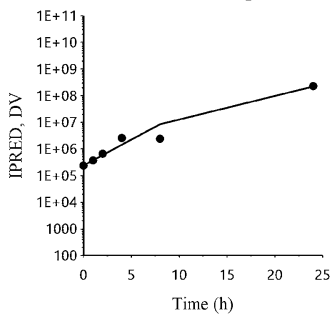

(2) $2 \mathrm{mg} / \mathrm{L}$

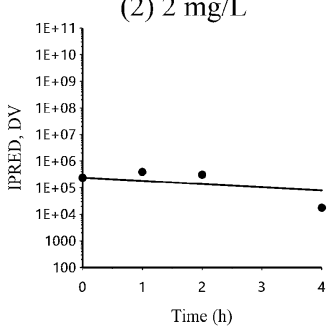

(2) Control

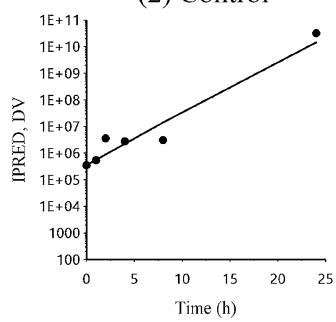

(1) $0.125 \mathrm{mg} / \mathrm{L}$

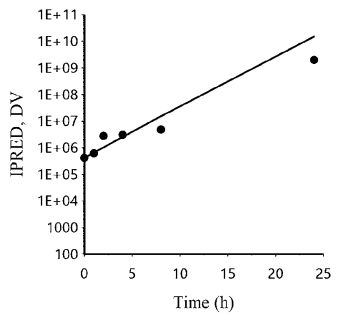

(1) $2 \mathrm{mg} / \mathrm{L}$

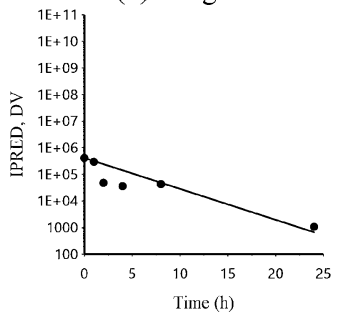

(2) $0.25 \mathrm{mg} / \mathrm{L}$

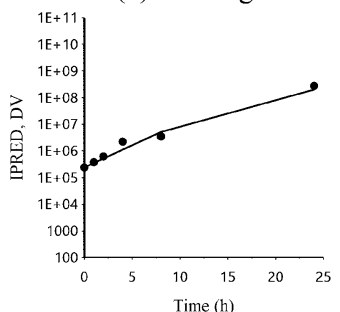

(2) $4 \mathrm{mg} / \mathrm{L}$

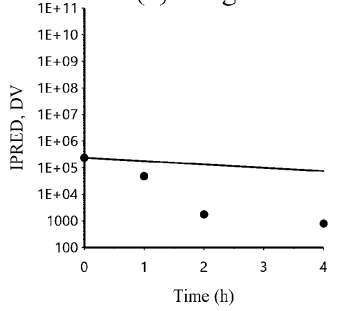

(2) Control

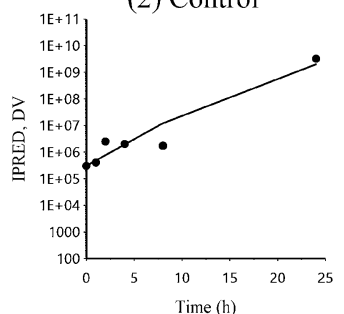

(1) $0.25 \mathrm{mg} / \mathrm{L}$

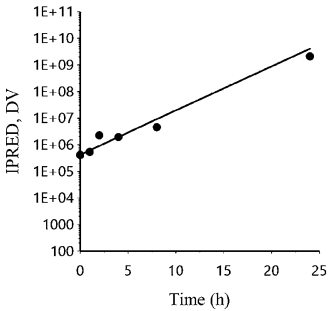

(1) $4 \mathrm{mg} / \mathrm{L}$

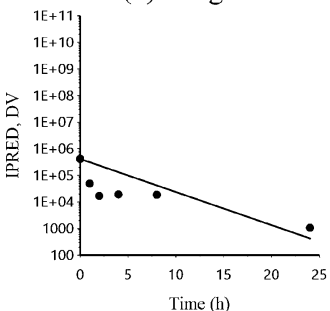

(2) $0.5 \mathrm{mg} / \mathrm{L}$

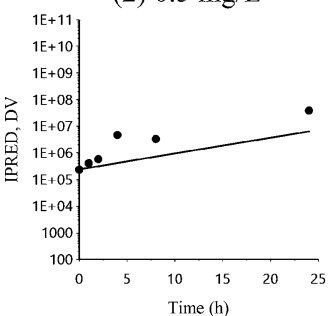

(1) Control

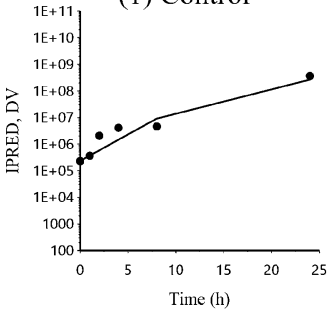

(1) $0.5 \mathrm{mg} / \mathrm{L}$

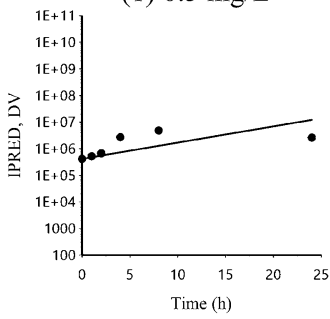

(2) Control

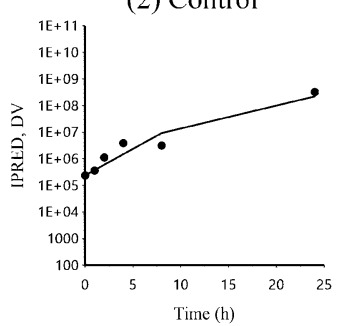

(2) $1 \mathrm{mg} / \mathrm{L}$

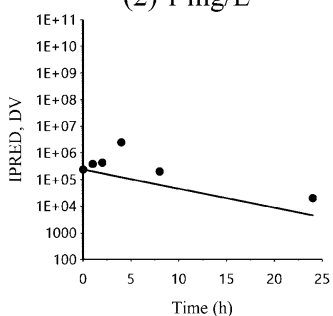

(1) Control

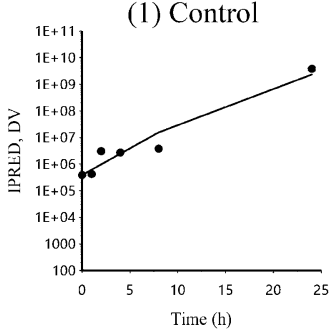

Figure 3 Plot (latticed by individual) of dependent variable (DV) i.e. observed bacterial concentration (black spots) and IPRED i.e. individual model predicted bacterial concentration (black line) of S. delphini vs time (h). DV: dependent variable i.e. observed bacterial concentration CFU/mL, IPRED: individual model predicted natural logarithm of bacterial concentration (CFU/mL). There were two S. delphini isolates at each TYL concentration in duplicate (the average of viable cell counts was used for each isolate), except for the control where the same two isolates were tested in triplicate. The two isolates were indicated by number 1 and 2 in brackets corresponding to the isolates ID of 16-12727-1 and 16-12403-3, respectively. 
Table 1 Estimation of primary and secondary PD parameters obtained from a model of the time kill experiment of TYL against S. delphini

\begin{tabular}{|c|c|c|c|}
\hline \multirow[t]{2}{*}{ Parameter } & \multirow[t]{2}{*}{ Units } & \multicolumn{2}{|l|}{ S. delphini } \\
\hline & & Mean & SE \\
\hline \multicolumn{4}{|l|}{ Primary parameters } \\
\hline $\mathrm{K}_{\mathrm{el}}$ & $1 / \mathrm{h}$ & 0 (fixed) & \\
\hline $\mathrm{K}_{\text {growthmax }}$ & $1 / \mathrm{h}$ & 0.63 & 0.017 \\
\hline $\mathrm{K}_{\text {death }}$ & $1 / \mathrm{h}$ & 0.17 (fixed)- & \\
\hline $\mathrm{B}_{\max }$ & $\mathrm{CFU} / \mathrm{mL}$ & $4.8 \times 10^{9}$ & $4.2 \times 10^{8}$ \\
\hline$E_{\max }$ & $1 / \mathrm{h}$ & 0.75 & 0.022 \\
\hline Gamma & Scalar & 2.73 & 0.275 \\
\hline $\mathrm{EC}_{50}$ & $\mathrm{mg} / \mathrm{L}$ & 0.55 & 0.026 \\
\hline SD & Scalar & 1.16 & 0.079 \\
\hline IIV B $B_{\max }(C V \%)$ & & 878 & 0.604 \\
\hline$\eta$ shrinkage $B_{\max }$ & & 0.02 & \\
\hline \multicolumn{4}{|c|}{ Secondary parameters } \\
\hline $\mathrm{MIC}$ & $\mathrm{mg} / \mathrm{L}$ & 0.36 & 0.023 \\
\hline $\mathrm{MBC}$ & $\mathrm{mg} / \mathrm{L}$ & 1.45 & 0.049 \\
\hline
\end{tabular}

$\mathrm{K}_{\mathrm{el}}$ is the drug degradation rate constant fixed as 0 to express no degradation of TYL during $24 \mathrm{~h}$ in a test tube, $\mathrm{K}_{\text {growthmax }}$ is the maximum growth rate constant of bacterial strains, $\mathrm{K}_{\text {death }}$ is the natural death rate constant of a bacterial strain that is equally present in the $\mathrm{S}$ and $\mathrm{P}$ compartments and was considered at a fixed rate of 0.17 per hour, $B_{\max }$ is the total bacterial count in the system $(\mathrm{S}+\mathrm{P}), \mathrm{E}_{\max }$ is the maximal effect of drug against bacterial species assessed by a maximal killing rate (efficacy), gamma ( $\left(\right.$ ) is the curve slope, $\mathrm{EC}_{50}$ is the concentration of drug that produces half of the maximal effect, $S D$ is standard deviation of the residual (exponential model for the control curves), IIV is interindividual (i.e. curve) variability expressed as coefficient of variation (CV\%), this variability corresponded to estimated post-hoc values of $B_{\max }$ from $1.86 \times 10^{8}$ to $3.58 \times 10^{10}$ for the 6 curves, Shrinkage refers to the quality of the estimated IIV, MIC and MBC are minimum inhibitory and bactericidal concentration of drug against bacterial species as estimated by the model. The precision of parameters (SE) was computed by the bootstrap tool in Phoenix ${ }^{\circledR}$.

into the tissues. The multiplicative component of the residual error was rather low as demonstrated by the $\mathrm{CV}$ of $15 \%$. The inclusion of the sample site (i.e. covariate) into the model for the plasma clearance did not reduce the BIC, and it was concluded that the sampling site (vein vs nail) had no influence on the plasma clearance. Hence, the clearance was estimated ignoring a possible effect of sampling site.

\section{Prediction of the PKPD index and PKPD target}

Escalating dose plots of TYL against $S$. delphini displaying four distinct MICs are presented in Figure 7. The simulated initial inoculum was fixed to $5 \times 10^{5} \mathrm{CFU} /$ $\mathrm{mL}$, and the final concentration of $30 \mathrm{CFU} / \mathrm{mL}$ was arbitrarily selected as the endpoint for a full bactericidal effect. Below this value, there was no possible regrowth and curves were truncated for computation of effects. The visual inspection of plots revealed that extremely high doses of TYL would be required to reach the bacterial baseline of $30 \mathrm{CFU} / \mathrm{mL}$. The initial $($ time $=0$ ) minimum required concentrations of TYL for $S$. delphini to reach the bacterial concentration baseline after $24 \mathrm{~h}$ with MICs of $0.125,0.25$ and $0.5 \mathrm{mg} / \mathrm{L}$ were 512 , 1024 and $2048 \times$ MIC, respectively, due to the rapid in vivo disappearance of TYL (see Discussion). The in silico simulations of killing upon TYL exposure allowed a comparison of the two possible PKPD indices, namely $f \mathrm{AUC}_{\mathrm{po}, 0-24 \mathrm{~h}} / \mathrm{MIC}$ and $f \mathrm{~T}(\%)>\mathrm{MIC}$. The curves are presented in Figure 8. Based on visual inspection of curves, there was a slightly better fit of data for $f \mathrm{AUC}_{\mathrm{po}, 0-24 \mathrm{~h}} /$ MIC compared to $f \mathrm{~T}(\%)>\mathrm{MIC}$, however the difference is not very noticeable. Table 3 presents the parameters of the $\mathrm{I}_{\max }$ model and goodness of fit values for an initial inoculum of $5 \times 10^{5} \mathrm{CFU} / \mathrm{mL}$. The mean index $_{50}$ for four MIC levels was $48.9 \mathrm{~h}$ for $f \mathrm{AUC}_{\mathrm{po}, 0-24 \mathrm{~h}} / \mathrm{MIC}$, indicating that the required in vivo concentration of TYL to achieve half of the maximal bacteriostatic effect, should be at least 2.04 fold the MIC (a scalar factor corresponding to the index ${ }_{50}$, divided by $24 \mathrm{~h}$ ). The mean index ${ }_{50}$ for $f \mathrm{~T}(\mathrm{~h})>\mathrm{MIC}$ was $12.1 \mathrm{~h}$, meaning the in vivo concentration of TYL should be above the MIC for at least $50 \%$ of the time during $24 \mathrm{~h}$ to achieve half of the maximal bacteriostatic effect. Based on the 28.4 points reduction in $\mathrm{AIC}$ for $f \mathrm{AUC}_{\mathrm{po}, 0-24 \mathrm{~h}} / \mathrm{MIC}$ compared to $f \mathrm{~T}(\%)>\mathrm{MIC}$ (Table 4), the former PKPD index was selected a priori for predicting the effect of TYL against $S$. delphini. The target values for $f \mathrm{AUC}_{\mathrm{po}, 0-24 \mathrm{~h}} / \mathrm{MIC}$ and $f \mathrm{~T}(\%)>\mathrm{MIC}$ are presented in Table 4. From simulations using four different MICs, the mean values for $f \mathrm{AUC}_{\mathrm{po}, 0-24 \mathrm{~h}} / \mathrm{MIC}$ with bacteriostatic and bactericidal effect of TYL against $S$. delphini were 48.9 and $98.7 \mathrm{~h}$, respectively. To express the PKPD index as a scalar value without dimension, these values were divided by $24 \mathrm{~h}$ [16], yielding 2.04 and 4.11 for bacteriostatic and bactericidal effect, respectively. This indicates that, in vivo average TYL plasma concentrations of two- and fourfold the MIC are required over a $24 \mathrm{~h}$ treatment interval to exert bacteriostatic and bactericidal effects, respectively.

\section{Prediction of TYL dosage regimen}

Considering the median of body clearance of $3.41 \mathrm{~L} / \mathrm{kg} / \mathrm{h}$, the oral bioavailability of $41 \%$, a mean free drug proportion of $69 \%$ (Table 2), the TECOFF of $2 \mathrm{mg} / \mathrm{L}$ [14] and the 4.11 target value of $f$ AUC/MIC for TYL against $S$. delphini for a bactericidal effect (Table 4), the computed daily oral dosage was $2378 \mathrm{mg} / \mathrm{kg}$ body weight using Eq. (9). For a bacteriostatic effect of TYL, considering the PKPD target of 2.04, the calculated daily dosage was $1180 \mathrm{mg} / \mathrm{kg}$. By using Monte Carlo Simulation (MCS), and the PK population model, PKPD cutoffs for the current empirical dosage of $10 \mathrm{mg} / \mathrm{kg}$ TYL once a day i.e. the maximal achievable MIC in a given percentage of the 


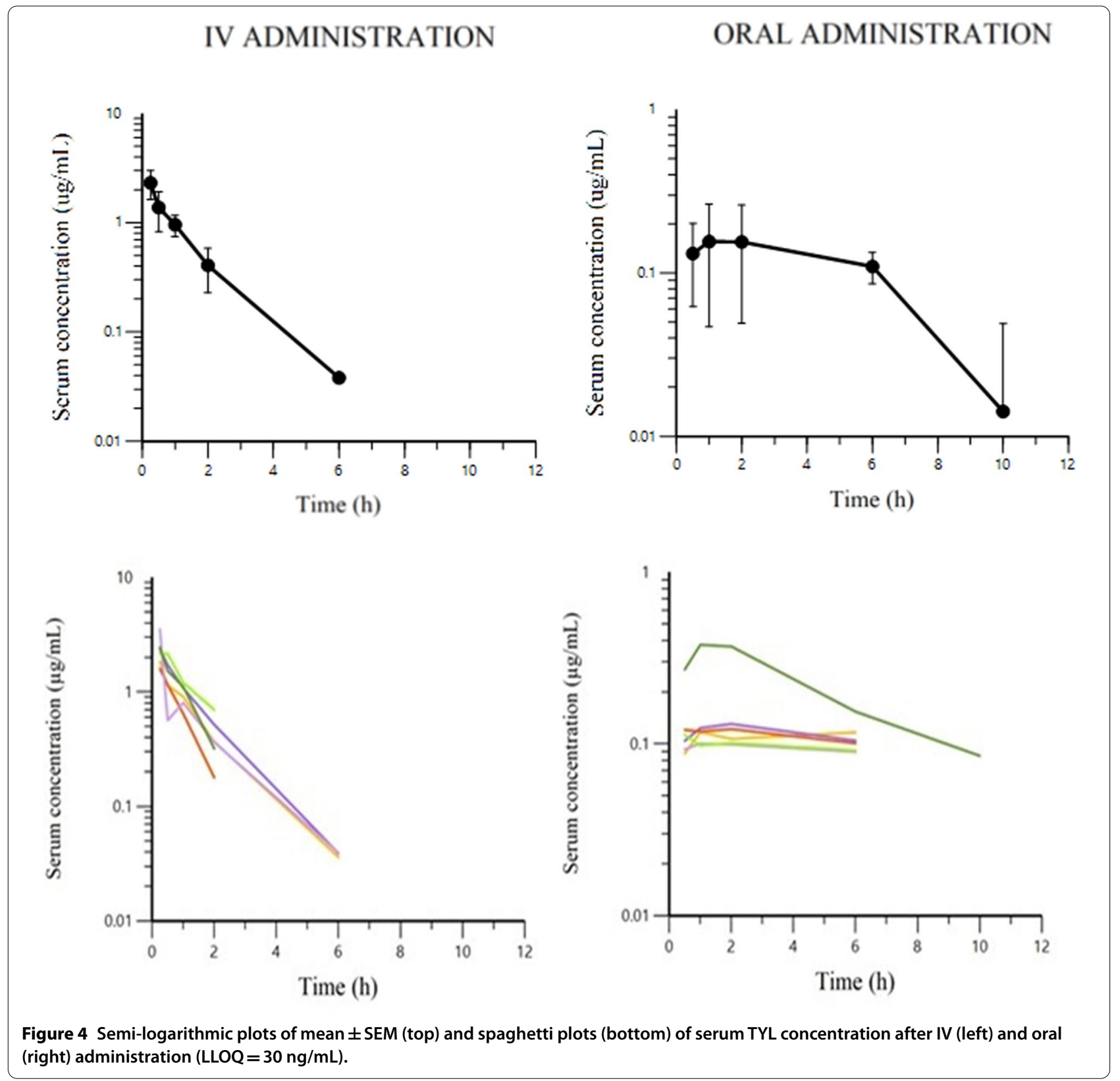

mink population [17] were 0.004 and $0.008 \mu \mathrm{g} / \mathrm{mL}$ with probability of target attainment (PTAs) of $90 \%$ and $50 \%$, respectively.

\section{Discussion}

Very few antimicrobial agents are registered for mink, hence most antimicrobial use in this species has to follow the cascade principle. This principle allows prescribing antimicrobials for use other than indicated in the product information. Such off-label use of antimicrobials is typically based on limited or no evidence for the target animal species and may therefore be accompanied by negative consequences including treatment failure and selection of antimicrobial resistance [18]. According to a recent recommendation by the European Medicines Agency (EMA), strategies to fight antimicrobial resistance should encourage the development of existing antimicrobials for use in minor species [19]. Our assessment of the validity of the current empiric TYL dosage regimen used in mink $(10 \mathrm{mg} / \mathrm{kg})$ is in line with that and with a recent recommendation to use a PKPD approach for optimizing dosage regimens of old antimicrobial agents with limited available clinical data [20]. 


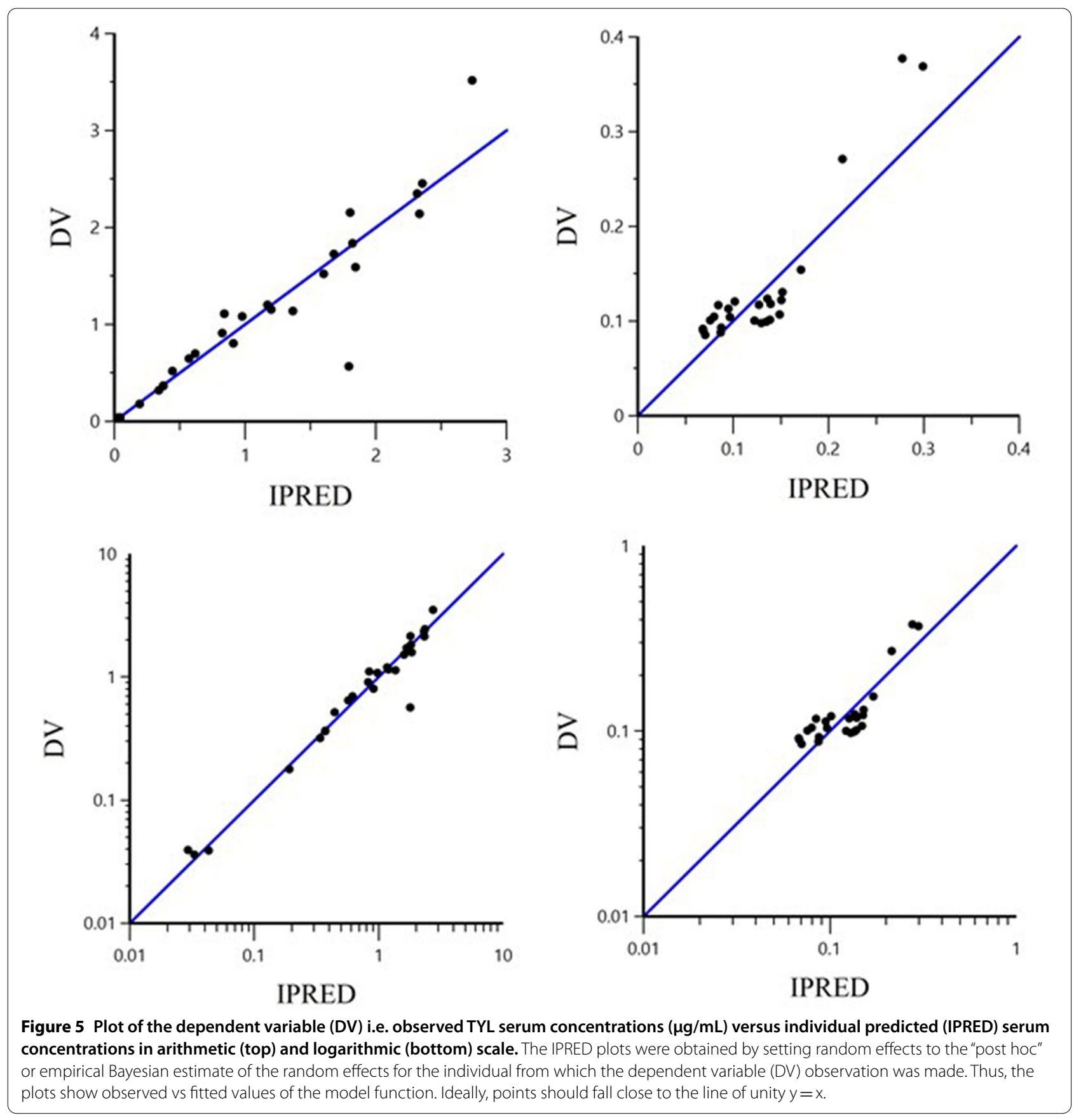

Overall, the disposition of TYL in mink upon oral administration of $10 \mathrm{mg} / \mathrm{kg}$ via feed was characterized by a relatively poor oral bioavailability, an extensive distribution and, overall, by a very high body clearance leading to plasma concentrations, which were always lower $\left(C_{\max }\right.$ of $0.43 \mathrm{mg} / \mathrm{L}$ ) than the $S$. delphini TECOFF of $2 \mathrm{mg} / \mathrm{L}$ [14]. Gastrointestinal absorption of TYL is generally rapid in monogastric animals with plasma concentrations peaking 1-3 $\mathrm{h}$ after oral dosing [21]. In line with this, we observed a peak plasma concentration already after $1.75 \mathrm{~h}$. The poor bioavailability of TYL in mink (41\%) is comparable to the 23 and $35 \%$ bioavailability of this drug reported in pigs [22] and chicken [23, 24], respectively. These rather low percentages might be due to the instability of TYL in acidic milieu like that of the stomach [25]. The steady-state volume of distribution (i.e. $\mathrm{V} 1+\mathrm{V} 2)$ was $3.5 \mathrm{~L} / \mathrm{kg}$ i.e. comparable to the findings in duck $(2.29 \mathrm{~L} / \mathrm{kg})$ [26] and chicken $(2.67 \mathrm{~L} / \mathrm{kg})$ [27]. This 

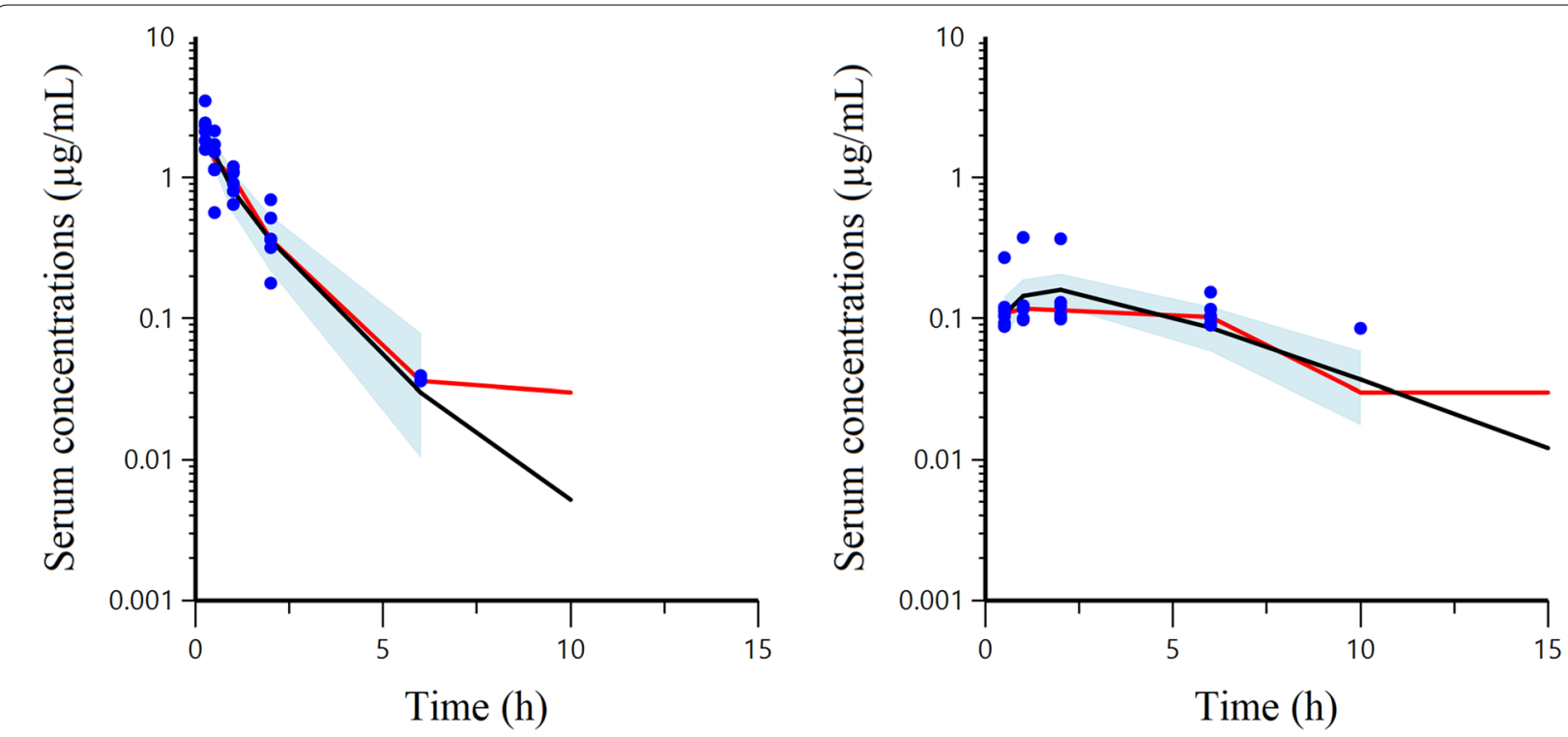

Figure 6 Visual Predictive Check (VPC) plots of observed serum concentration ( $\mu \mathrm{g} / \mathrm{mL}$ ) of TYL vs. time (h) and observed and predicted quantiles. The VPC diagnostic plots illustrate the trends with the observed 50\% quantiles (red line) and predictive check 50\% quantile (black line) that were computed using Monte Carlo simulation over the observed serum concentrations (blue spots) following IV (left) and oral (right) administration. The blue shaded area corresponds to the $95 \%$ confidence interval of the $50 \%$ simulated quantile (black line).

extensive tissue distribution is a common trait of macrolides, which as weak bases become entrapped in cells that are more acidic than plasma, e.g. in the cells of lung, liver, kidney and heart $[21,28]$. The most noticeable characteristic of TYL disposition in mink was the very high body clearance $(3.41 \mathrm{~L} / \mathrm{h} / \mathrm{kg})$. The AUC is controlled by body clearance and bioavailability following extravascular administration of a drug [29]. The rapid clearance and poor bioavailability of TYL in mink resulted in an AUC/ dose ratio $\left(0.331\right.$ and $0.091 \mu \mathrm{g} \mathrm{h} \mathrm{mL} L^{-1} / \mathrm{mg} \mathrm{kg}^{-1}$ after IV and oral administration, respectively) about three times lower than reported in chicken $\left(0.25 \mu \mathrm{g} \mathrm{h} \mathrm{mL}{ }^{-1} / \mathrm{mg} \mathrm{kg}^{-1}\right.$ after oral administration) [23] and duck $\left(0.3 \mu \mathrm{g} \mathrm{h} \mathrm{mL} \mathrm{L}^{-1} /\right.$ mg. $\mathrm{kg}^{-1}$ after oral administration) [26], and 14 times lower than in $\operatorname{dog}\left(4.74 \mu \mathrm{g} \mathrm{h} \mathrm{mL}{ }^{-1} / \mathrm{mg} \mathrm{kg}^{-1}\right.$ after an IV administration) [30]. This means that a much higher dose of TYL would be required in mink compared to these other animals in order to reach the same AUC levels.

In the first in vivo study on drug disposition after IV administration, we withdrew blood from both the cephalic vein and nails of mink in order to compare PK results and assess whether nail blood may replace venous blood, which is typically used to analyze drug disposition. There was no statistical difference in the computed clearance between venous and nail blood samples obtained in parallel when using a model with and without a covariate for the sampling site. Therefore, to avoid the additional step of anesthesia, we decided to take only nail blood in the subsequent in vivo study on TYL bioavailability.
Beyond PK properties, the second component of a dosage regimen is the drug PD properties. To deal with the intrinsic shortage of the MIC value, namely its failure to elucidate dynamic rather than static effects of an antimicrobial during exposure $[11,31,32]$, an in vitro semimechanistic model for analysis of time-kill experiments was used in this study. In this PD model, a random component was added in the model for $B_{\max }$ for each tested dose level, because $B_{\max }$ structurally reflects differences between the strains (such as $\mathrm{K}_{\text {growth }}$ ), and in addition because $B_{\max }$ is directly observable for each curve and its value has been estimated with low shrinkage. Also, the inclusion of the random component on $\mathrm{B}_{\max }$ improved the precision of the estimations for pharmacodynamic parameters. This model allowed us to obtain the three genuine PD parameters, namely efficacy, potency and sensitivity of TYL against $S$. delphini (Table 1). In addition, PKPD modeling based on the in vitro time-kill experiment and in vivo TYL disposition in mink, offered an alternative approach to select and estimate the PKPD index instead of the traditionally used in vivo rodent models with concurrent ethical and financial issues. In general, macrolides are considered time-dependent antimicrobials, but for some macrolides producing a prolonged persistent effect (e.g. azithromycin) the $f \mathrm{AUC} /$ MIC is an appropriate predictor of effect and can be used as PKPD index $[6,13,33,34]$. The selection of $f$ AUC/MIC as PKPD index in this study was based on AIC reduction (Table 3) and was in agreement with previous studies on 
Table 2 Population primary and secondary parameters of TYL estimated with a two-compartment model by fitting IV and oral PK data simultaneously

\begin{tabular}{|c|c|c|c|c|}
\hline & \multirow[t]{2}{*}{ Parameter } & \multirow[t]{2}{*}{ Units } & \multicolumn{2}{|c|}{ IV and oral } \\
\hline & & & TV & SE \\
\hline \multirow[t]{13}{*}{ Primary parameters } & $\mathrm{Ka}$ & $1 / \mathrm{h}$ & 0.23 & 0.023 \\
\hline & $V_{1}$ & $\mathrm{~L} / \mathrm{kg}$ & 2.24 & 1.076 \\
\hline & $V_{2}$ & $\mathrm{~L} / \mathrm{kg}$ & 1.33 & 0.523 \\
\hline & $\mathrm{CL}$ & $\mathrm{L} / \mathrm{h} / \mathrm{kg}$ & 3.41 & 0.756 \\
\hline & Q & $\mathrm{L} / \mathrm{h} / \mathrm{kg}$ & 1.97 & 1.453 \\
\hline & $\mathrm{F}$ & & 0.41 & 0.150 \\
\hline & MultiSD & Scalar & 0.15 & 0.114 \\
\hline & SDIV & $\mu \mathrm{g} / \mathrm{mL}$ & 0.020 & 0.007 \\
\hline & SD Oral & $\mu \mathrm{g} / \mathrm{mL}$ & 0.006 & 0.006 \\
\hline & $B S V V_{1}(C \vee \%)$ & & 21.21 & 0.079 \\
\hline & BSV CL (CV\%) & & 10.00 & 0.161 \\
\hline & $\eta$ shrinkage $V_{1}$ & & 0.12 & \\
\hline & ๆ shrinkage CL & & 0.20 & \\
\hline \multirow[t]{5}{*}{ Secondary parameters } & $A \cup C_{I V}$ & $\mu \mathrm{gh} / \mathrm{mL}$ & 3.05 & 0.565 \\
\hline & $A \cup C_{\text {Oral }}$ & $\mu \mathrm{gh} / \mathrm{mL}$ & 1.18 & 0.195 \\
\hline & $\mathrm{Ka}_{\mathrm{HL}}$ & h & 3.00 & 0.319 \\
\hline & $\mathrm{T}_{\max }$ & h & 1.75 & 0.138 \\
\hline & $\mathrm{C}_{\max }$ & $\mu \mathrm{g} / \mathrm{mL}$ & 0.43 & 0.072 \\
\hline
\end{tabular}

$\mathrm{Ka}$ is the absorption rate constant, $\mathrm{V}_{1}$ and $\mathrm{V}_{2}$ are volumes of distribution in central and peripheral compartments, respectively, $\mathrm{CL}$ is body clearance, $\mathrm{Q}$ is inter-compartment clearance, MultiSD is multiplicative error term and it should be interpreted as a coefficient of variation, (here of 15\%), SD is the additive component of the error term, BSV is between subject variability expressed as $\mathrm{CV}$, Shrinkage refers to the quality of the estimated BSV. For the present study, an $\eta$-shrinkage lower than 0.4 has been considered as acceptable. $A U C_{I V}$ and $A \cup C_{O r a l}$ are area under the concentration-time curve after IV and oral dosing, respectively and $\mathrm{Ka}_{-\mathrm{HL}}$ is half-life of absorption. TV is the population typical value. The precision of parameters $(\mathrm{SE})$ was computed by the bootstrap tool in Phoenix ${ }^{\circledR}$.

TYL in pig [35] and duck [26]. In our simulations for predicting a PKPD target, we selected $30 \mathrm{CFU} / \mathrm{mL}$ as a lower limit where no bacterial re-growth would be possible to capture all the curves of bacterial evolution, although for a non-immunocompromised subject, the natural process of bacterial eradication by the immune system can be efficient up to $10^{5} \mathrm{CFU} / \mathrm{mL}$ [36]. We selected the one$\log _{10}$ reduction of the initial bacterial concentration as a relevant endpoint of efficacy for the in vivo situation to estimate the PKPD target. This is a univocal efficacy endpoint that is targeted in human medicine [37]. The estimated $f \mathrm{AUC}_{\mathrm{po}, 0-24 \mathrm{~h}} / \mathrm{MIC}$ for bacteriostatic and bactericidal effects was 48.9 and $98.7 \mathrm{~h}$, respectively. It has been suggested to divide $f$ AUC/MIC by 24 h to generate a scaling factor without a time dimension. This scaling factor simplifies the understanding of $f$ AUC/MIC and has clinical application [16]. In this study, the scaling factors for bacteriostatic and bactericidal effects of TYL were 2.04 and 4.11 , respectively. These scaling factors mean that the goal for a rational dosage is to maintain a plasma concentration equal to 2 or fourfold the MIC to comply with PKPD results, and these figures can be directly incorporated into the dosage Eq. (9) for daily dose determination [16].

Using this approach, we computed extremely high and unachievable oral dosages of 2378 and $1180 \mathrm{mg} / \mathrm{kg}$ for bactericidal and bacteriostatic effects, respectively, to target the $S$. delphini wildtype population with TYL MICs equal to or lower than the TECOFF of $2 \mathrm{mg} / \mathrm{L}$. As explained above, this high dosage is a result of the very high clearance and low bioavailability of TYL in mink combined with a rather high TYL TECOFF of $2 \mathrm{mg} / \mathrm{L}$ for S. delphini. By considering the PKPD cutoffs of 0.008 and $0.004 \mu \mathrm{g} / \mathrm{mL}$ for the currently used dosage of $10 \mathrm{mg} /$ $\mathrm{kg}$ with $50 \%$ and $90 \%$ probability of target attainment in mink populations, respectively, and by comparing these cutoff values with the TECOFF of $2 \mathrm{mg} / \mathrm{L}$ for $S$. delphini, it can be deduced that at least 250 and 500 times the currently used dosage of $10 \mathrm{mg} / \mathrm{kg}$ TYL would be required for treatment of S. delphini infections. The very high calculated dose in mink is consistent with the fact that in chickens an oral dose of $100 \mathrm{mg} / \mathrm{kg} /$ day does not allow plasma concentrations to exceed $0.4 \mu \mathrm{g} / \mathrm{mL}$ despite the oral clearance in chickens being 3 times lower than in mink [38].

It should be noted that the calculated dose may be higher than actually needed due to a possible bias when measuring MICs. In that regard, it has recently been shown that the MICs of tulathromycin for Mannheimia haemolytica and Pasteurella multocida were 50 times lower in calf serum than in MHB [39]. Accordingly, it cannot be excluded that the TECOFF measured in MHB was overestimated compared to what it would have been using serum. Another point is the TYL anti-inflammatory properties, which can modulate COX-2 and iNOS gene expression and the production of cytokines by immune cells [40]. Although this boosting effect on the immune system and a potential effect of serum may partially contribute to a clinical effect of TYL in minks, these factors are not likely to reduce the TYL dose to a sufficiently low level. The same is true when taking into consideration other potential target pathogens, e.g. Streptococcus canis, which is a less 

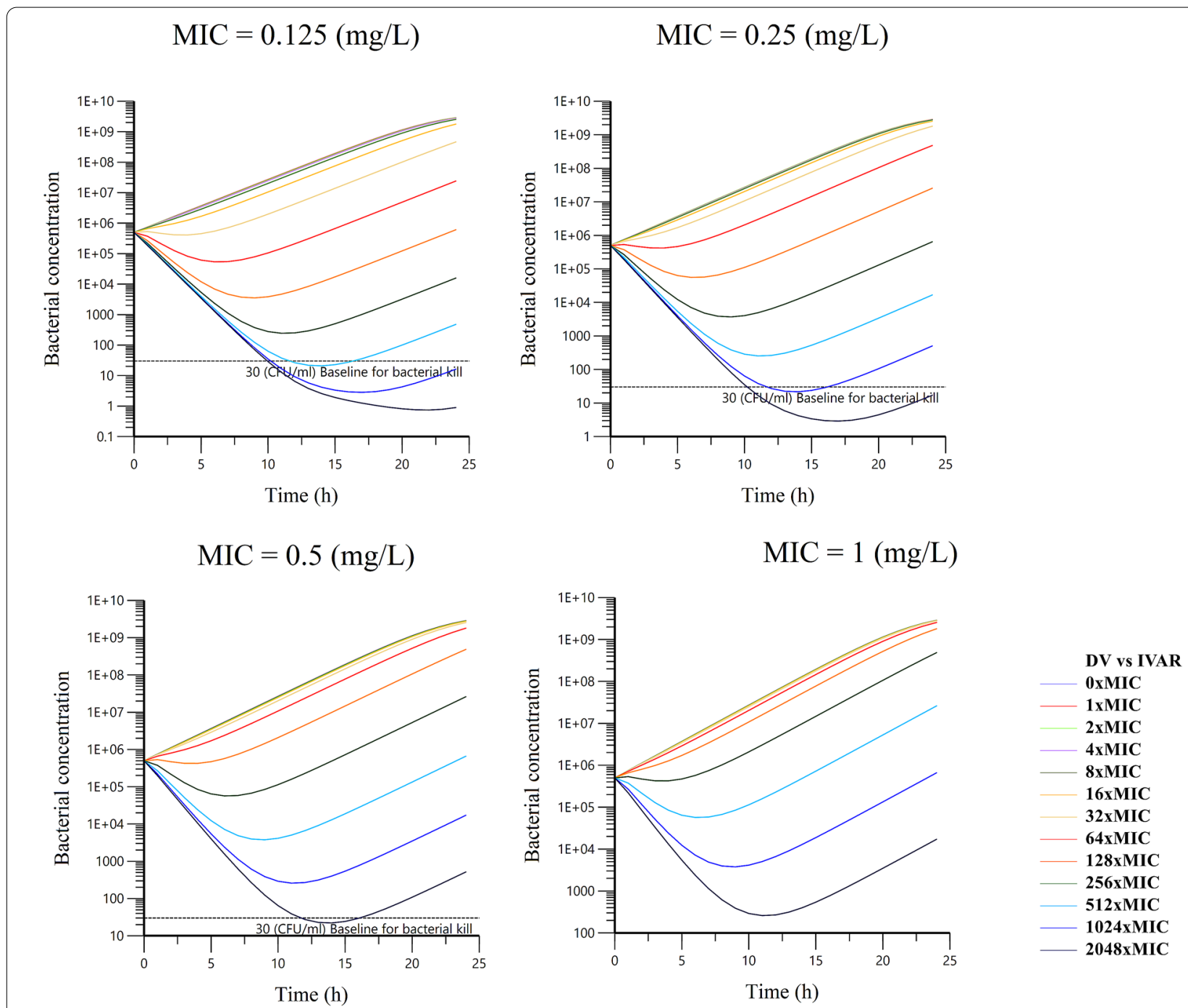

Figure 7 Escalating dose plots of $\mathbf{1 3}$ daily oral TYL doses against S. delphini displaying four different TYL MICs. The x-axis represents time after dosing (h) and the $y$-axis represents total bacterial concentration (CFU/mL). The baseline for bacterial kill $(30 \mathrm{CFU} / \mathrm{mL})$ was arbitrarily defined as the baseline for bacterial concentration that can be eliminated by the immune system.

common cause of infections (e.g. of the skin) in mink [2]. Although this opportunistic pathogen has a lower TECOFF $(0.25 \mathrm{mg} / \mathrm{L})$ than $S$. delphini [14], very high dosages of 297 and $148 \mathrm{mg} / \mathrm{kg}$ would be needed for bactericidal and bacteriostatic effects against $S$. canis. It should be noted that these calculations are associated with some uncertainty, as they are based on the same PKPD target as determined for S. delphini. One potential limitation in our in vivo experiments is the use of an analgesic and anesthesia, which was necessary for practical and ethical reasons. The use of such drugs may influence the disposition of TYL due to alterations of biological functions like cardiac output and blood flow to internal organs [41]. Although this evidence relies on studies in humans, we cannot exclude that meloxicam and sevoflurane affected TYL disposition in mink and consequently our results. However, these possible effects are not likely to question our conclusions 


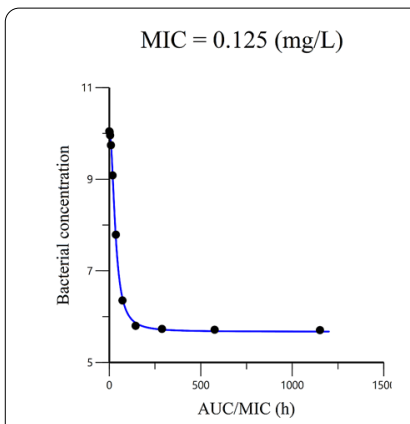

$\mathrm{MIC}=0.25(\mathrm{mg} / \mathrm{L})$

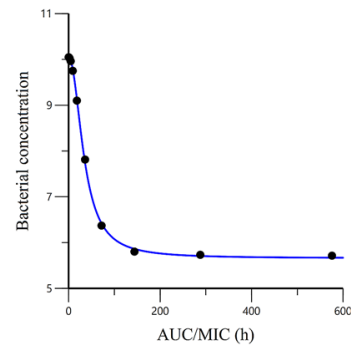

$\mathrm{MIC}=0.25(\mathrm{mg} / \mathrm{L})$
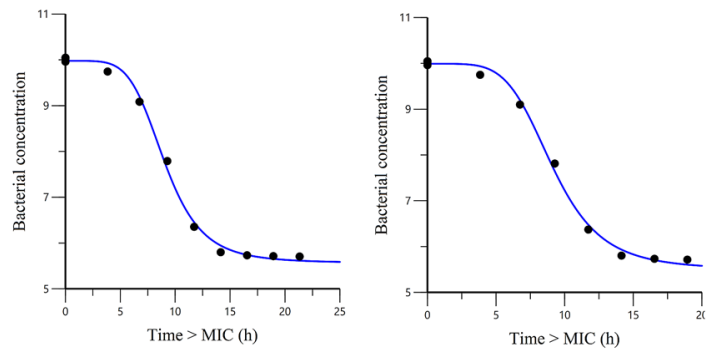

$\mathrm{MIC}=0.5(\mathrm{mg} / \mathrm{L})$

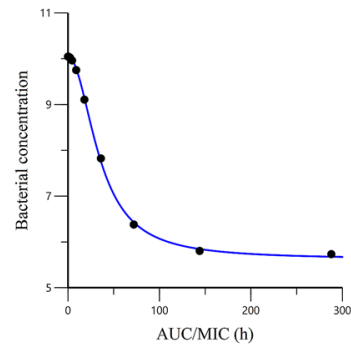

$\mathrm{MIC}=0.5(\mathrm{mg} / \mathrm{L})$

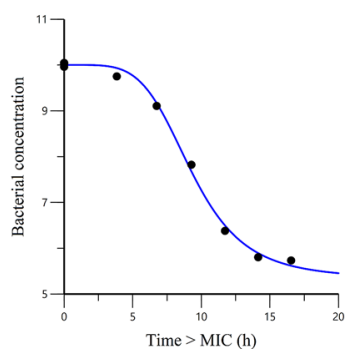

$\mathrm{MIC}=1(\mathrm{mg} / \mathrm{L})$

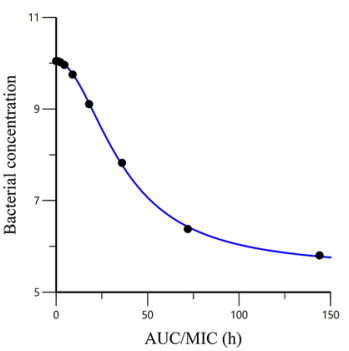

$\mathrm{MIC}=1(\mathrm{mg} / \mathrm{L})$

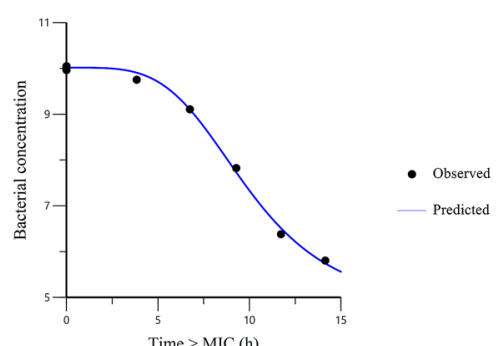

Figure 8 The observed vs. predicted values of the $I_{\max }$ Sigmoidal model for fAUC/MIC (top) and fT > MIC (bottom) of TYL against S. delphini displaying four distinct TYL MICs. The $y$-axis represents the $\log _{10}$ bacterial concentration (CFU/mL), and the $x$-axis represents different values for the PKPD index ( $F A U C / M I C$ and $f T>M I C$ ).

Table 3 Mean and SE of estimated $I_{\max }$ sigmoidal model parameters for $f A U C / M I C$ and $f T>M I C$ of TYL against MICs in S. delphini

\begin{tabular}{|c|c|c|}
\hline Parameters & $f A U C_{p o, 0-24 h} / M I C(h)$ & $f \mathrm{~T}>\mathrm{MIC}(\mathrm{h})$ \\
\hline \multicolumn{3}{|l|}{$I_{\max }$} \\
\hline Mean & 4.15 & 5.05 \\
\hline SE & 0.09 & 0.15 \\
\hline \multicolumn{3}{|l|}{ Index 50} \\
\hline Mean & 48.95 & 12.06 \\
\hline SE & 1.66 & 0.15 \\
\hline \multicolumn{3}{|l|}{$E_{0}$} \\
\hline Mean & 10.47 & 10.43 \\
\hline SE & 0.02 & 0.01 \\
\hline \multicolumn{3}{|l|}{ Gamma } \\
\hline Mean & 1.75 & 3.50 \\
\hline SE & 0.08 & 0.14 \\
\hline AIC & -57.8 & -29.4 \\
\hline$R^{2}$ & 0.9997 & 0.997 \\
\hline \multicolumn{3}{|c|}{$\begin{array}{l}\mathrm{I}_{\max }\left(\log _{10} \text { transformation of bacterial concentration (CFU/mL)) is magnitude }\right. \\
\text { of the maximal effect of TYL, the index } x_{50} \text { is magnitude of the PKPD index (fAUC } \\
\text { po,0-24 } / \mathrm{MIC}(\mathrm{h}) \text { or } f \mathrm{f}>\mathrm{MIC}(\mathrm{h})) \text { that achieves } 50 \% \text { of the maximal effect, } \mathrm{E}_{0}\left(\mathrm{Log}_{10}\right. \\
\text { transformation of bacterial concentration (CFU/mL)) is maximum effect in the } \\
\text { absence of antimicrobial (obtained from control group), and gamma }(\mathrm{\gamma}) \text { is the } \\
\text { sigmoidicity factor, reflecting the steepness of the relationship. AIC is Akaike's } \\
\text { information criterion, with lower AIC indicating better fit of data to the model. } \mathrm{R}^{2} \\
\text { is the coefficient of determination, indicating the amount of variation explained } \\
\text { by the model. }\end{array}$} \\
\hline
\end{tabular}

that TYL cannot be used to treat a systemic infection in mink when the MIC of a wild-type population is as high as $2 \mathrm{mg} / \mathrm{L}$.

Using a PKPD approach, TYL can be considered either as a concentration or a time-dependent antimicrobial agent for $S$. delphini. Considering TYL as concentration-dependent, a bacteriostatic and bactericidal effect against $S$. delphini can be obtained with $f_{\mathrm{AUC}} \mathrm{po}, 0-24 \mathrm{~h}_{\mathrm{h}} / \mathrm{MIC}$ of $48.9 \mathrm{~h}$ and $98.7 \mathrm{~h}$, respectively. The daily dosage of TYL against this pathogen was predicted to be 2378 and $1180 \mathrm{mg} / \mathrm{kg}$ for bactericidal and bacteriostatic effects, respectively. Although the wildtypes of other mink pathogens such as $S$. canis have lower MICs, required dosages are notably higher than the currently used off-label dosage of $10 \mathrm{mg} / \mathrm{kg}$, and these dosages are simply impossible to reach in practice due to the risk of toxicity. The PKPD cutoff for the currently used dosage of $10 \mathrm{mg} / \mathrm{kg}$ once a day was $0.004 \mathrm{mg} / \mathrm{L}$ with PTA $90 \%$. Therefore, the current TYL dose for treatment of extra-intestinal mink infections is not supported by PKPD data and should be avoided to minimize the risk of treatment failure and selection of antimicrobial resistance. 
Table 4 Calculated PK/PD targets for a bacteriostatic and bactericidal effect, respectively, of TYL against S. delphini

\begin{tabular}{|c|c|c|c|c|c|c|c|}
\hline & \multicolumn{2}{|c|}{$f A U C_{p o, 0-24 h} / M I C(h)$} & \multicolumn{2}{|c|}{$\left(f_{A U C}{ }_{p o, 0-24 h} / M I C\right) / 24$ Scalar } & \multicolumn{2}{|l|}{$f \mathrm{~T}>\mathrm{MIC}(\mathrm{h})$} & \multirow{2}{*}{$\begin{array}{l}f T>M I C(\%) \\
B_{\text {cidal }}\end{array}$} \\
\hline & $B_{\text {static }}$ & $\mathrm{B}_{\text {cidal }}$ & $B_{\text {static }}$ & $\mathrm{B}_{\text {cidal }}$ & $B_{\text {static }}$ & $\mathrm{B}_{\text {cidal }}$ & \\
\hline Average & $48.91( \pm 0.3)$ & $98.72( \pm 0.9)$ & $2.04( \pm 0.01)$ & $4.11( \pm 0.04)$ & $10.30( \pm 0.04)$ & $13.20( \pm 0.06)$ & $55( \pm 0.26)$ \\
\hline
\end{tabular}

The value for $f A U C{ }_{{ }_{2-2}} / \mathrm{MIC}(\mathrm{h})$ presents the required area under the concentration-time curve of TYL over MIC, and $f T>M I C$ (\%) is the required duration of serum concentration of TYL above MIC. The PKPD targets were obtained ( $m$ ean \pm SE from an $I_{\max }$ sigmoidal model for predicted bacteriostatic and bactericidal effects corresponding to no change and one $\log _{10}$ reduction, respectively, of initial bacterial concentration after $24 \mathrm{~h}$. Scalar fAUC/MIC was obtained by dividing the AUC/ MIC cutoff by $24 \mathrm{~h}$.

\section{Supplementary Information}

The online version contains supplementary material available at https://doi. org/10.1186/s13567-021-00906-0.

\section{Additional file 1. Quantification of TYL in samples. \\ Additional file 2. Plots for PD modeling of TYL against S. delphini. Additional file 3. PK plots obtained from NLME.}

\section{Abbreviations}

AIC: Akaike's Information Criteria; Alpha- ${ }_{\mathrm{HL}}$ : Distribution half-life; AUC: Area under the time-concentration curve; Beta- ${ }_{H L}$ : Elimination half-life; BQL: Below Quantification Limit; $B_{\text {max }}$ : Maximum achievable bacterial concentration in the system; BSV: Between subject variability; CL: Body clearance; $C_{\text {max }}$ : Maximal serum concentration; DV: Dependent Variable; (T)ECOFF: (Tentative) Epidemiological cut off; $E_{0}$ : Effect at the baseline; $E_{50}$ : The concentration of drug that produces half the maximum effects; ETA ( $\eta$ ): Random effect describing the deviation of the individual empirical Bayes estimate of the parameter from the typical population parameter estimate; $f$ : Free fraction of drug; F: Bioavailability of drug; Gamma ( $\gamma$ ): Hill coefficient, sigmoidicity factor; $I C_{50}$ : Concentration producing half the maximum inhibitory effect; IPRED: Individual predicted value based on individual's ETAs; I max: Maximum inhibitory effect; Ka: Absorption rate constant; $\mathrm{Ka}_{-\mathrm{HL}}$ : Absorption half-life; $\mathrm{K}_{\text {death: }}$ : Bacterial natural death rate constant; $\mathrm{K}_{\mathrm{el}}$ : Degradation constant of drug in the test tube condition; $\mathrm{K}_{\text {growth }}$ : Bacterial growth rate constant; $K_{\text {growthmax }}$ :Maximum achievable bacterial growth constant; LLOQ: lower limit of quantification; MBC: Minimum bactericidal concentration; MHA: Muller Hinton Agar; MHB: Muller Hinton Broth; MIC: Minimum inhibitory concentration; OMEGA $\left(\omega^{2}\right)$ : Matrix of between subject variance; PD: Pharmacodynamics; PK: Pharmacokinetic; Q: Inter-compartmental clearance; SF: scaling factor; SIGMA $\left(\sigma^{2}\right)$ : Residual variance; TAD: Time after dosing; $T_{\max }$ :Time at maximum serum concentration; TYL: Tylosin; $V_{1}$ : Volume of distribution in central compartment; $V_{2}$ : Volume of distribution in peripheral compartment; VPC: Visual predictive check.

\section{Acknowledgements}

The authors would like to thank Mette Fertner (Kopenhagen Fur, Denmark), Mattia Pirolo (University Roma Tre, Italy), Nanett Kvist Nikolaisen (Technical University of Denmark, Denmark), Helle Harding Poulsen (University of Copenhagen, Denmark), Anne Sofie Vedsted Hammer (University of Copenhagen, Denmark), Connie Frank Matthiesen (University of Copenhagen, Denmark), Ann-Mona Kulsø Larsen (Henrik Nordgaard Hansen, Denmark), Kopenhagen Fur research farm (Holstebro, Denmark), and the Section for Experimental Animal Models at the Department of Veterinary and Animal Sciences, University of Copenhagen, for their assistance with in vitro and animal experiments.

\section{Authors' contributions}

AAR provided raw PK and PD data and drafted the manuscript. JMB, TS, PD, and AAR conducted animal experiments. HLF conducted quantification and analytical processes of blood samples. PL-T and AAR performed modeling and analysis. PD and TS supervised the project. All authors read and approved the final manuscript.

\section{Funding}

This work was supported by the Danish fur breeder association (Dansk Pelsdyravlerforenings Forskningsfond) and the Innovation Fund Denmark [Grant no.: 5189-00060B]

\section{Availability of data and materials}

The datasets and model files generated during the current study were created in the Mendeley Data platform, http://dx.doi.org/10.17632/wxc782dhkd.1

\section{Ethics approval and consent to participate}

All animal experiments in this study were approved by the Danish Animal Experiments Inspectorate (Permit No. 2017-15-0201-01291) and by the Danish Medicines Agency (Permit No. 2017083950).

\section{Competing interests}

The authors declare that they have no competing interests.

\section{Author details}

${ }^{1}$ Department of Veterinary and Animal Sciences, University of Copenhagen, Stigbøjlen 4, 1870 Frederiksberg C, Denmark. ${ }^{2}$ Department of Veterinary and Animal Sciences, University of Copenhagen, Ridebanevej 3, 1870 Frederiksberg C, Denmark. ${ }^{3}$ National Food Institute, Technical University of Denmark, Kemitorvet, Building 204, 2800 Kongens Lyngby, Denmark. ${ }^{4}$ Kopenhagen Diagnostics, Department of Health and Diagnostics, Kopenhagen Fur a.m.b.a., Langagervej 60, 2600 Glostrup, Denmark. ${ }^{5}$ Royal Veterinary College, University of London, Hawkshead Campus, Hatfield AL9 7TA, UK. ${ }^{6}$ INTHERES, Université de Toulouse, INRA, ENVT, 23 Chemin des Capelles, BP 87614, 31076, Toulouse Cedex 3, France.

Received: 14 July 2020 Accepted: 14 January 2021

Published online: 27 February 2021

\section{References}

1. Guardabassi L, Schmidt KR, Petersen TS, Espinosa-Gongora C, Moodley A, Agers $\varnothing$ Y, Olsen JE (2012) Mustelidae are natural hosts of Staphylococcus delphini group A. Vet Microbiol 159:351-353. https://doi.org/10.1016/j. vetmic.2012.04.004

2. Chalmers G, McLean J, Hunter DB, Brash M, Slavic D, Pearl DL, Boerlin P (2015) Staphylococcus spp., Streptococcus canis, and Arcanobacterium phocae of healthy Canadian farmed mink and mink with pododermatitis. Can J Vet Res 79:129-135. https://ingentaconnect.com/content/cvma/ cjvr/2015/00000079/00000002/art00007

3. Jespersen A, Hammer AS, Jensen HE, Bonde-Jensen N, Lassus MM, Agger JF, Larsen PF (2015) Foot lesions in farmed mink (Neovison vison): pathologic and epidemiologic characteristics on 4 Danish farms. Vet Pathol 53:666-673. https://doi.org/10.1177/0300985815600502

4. Shryock TR, Mortensen JE, Baumholtz M (1998) The effects of macrolides on the expression of bacterial virulence mechanisms. J Antimicrob Chemother 41:505-512. https://doi.org/10.1093/jac/41.5.505

5. Europeans Medicines Agency (2018) Reflection paper on off-label use of antimicrobials in veterinary medicine in the European Union. EMA/ CVMP/AWP/237294/2017. https://www.ema.europa.eu/en/documents/ 
scientific-guideline/reflection-paper-label-use-antimicrobials-veterinary -medicine-european-union-first-version_en.pdf. Accessed 18 Dec 2018

6. Craig WA (2001) Does the dose matter? Clin Infect Dis 33:S233-S237. https://doi.org/10.1086/321854

7. Ronaghinia AA, Nikolaisen NK, Hansen SG, Poulsen HH, Frandsen HL, Struve T, Toutain P-L, Damborg P (2021) Validating an empiric sulfadiazine-trimethoprim dosage regimen for treatment of Escherichia coli and Staphylococcus delphini infections in mink (Neovison vison). J Vet Pharmacol Ther 44:93-106. https://doi.org/10.1111/jvp.12894

8. Villa RE, Prandini E, Caloni F, Carli S (1997) Serum protein binding of some sulfonamides, quinolones and fluoroquinolones in farm and domestic animals. J Vet Pharmacol Ther 20(suppl 1):34-35

9. CLSI (2015) Performance Standards for antimicrobial disk and dilution susceptibility tests for bacterial isolated from animals, Third Edition, VET01, $3^{\text {rd }}$ edn. Wayne, PA

10. Nielsen El, Viberg A, Löwdin E, Cars O, Karlsson MO, Sandström M (2007) Semimechanistic pharmacokinetic/pharmacodynamic model for assessment of activity of antibacterial agents from time-kill curve experiments. Antimicrob Agents Chemother 51:128-136. https://doi.org/10.1128/ AAC.00604-06

11. Mouton JW, Vinks AA (2005) Pharmacokinetic/pharmacodynamic modelling of antibacterials in vitro and in vivo using bacterial growth and kill kinetics. Clin Pharmacokinet 44:201-210. https://doi.org/10.2165/00003 088-200544020-00005

12. Beal SL (2001) Ways to fit a PK model with some data below the quantification limit. J Pharmacokinet Pharmacodyn 28:481-504. https://doi. org/10.1023/A:1012299115260

13. Nielsen El, Cars O, Friberg LE (2011) Pharmacokinetic/pharmacodynamic (PK/PD) indices of antibiotics predicted by a semimechanistic PKPD model: a step toward model-based dose optimization. Antimicrob Agents Chemother 55:4619-4630. https://doi.org/10.1128/AAC.00182-11

14. Nikolaisen NK, Ronaghinia AA, Lassen DCK, Chehabi CN, Lindegaard M, Struve T, Chriél M, Damborg P, Kahlmeter G, Jensen LB, Pedersen K (2020) Employing MIC data for mink pathogens to propose tentative epidemiological cut-off values: a step toward rationalizing antimicrobial use in mink. Front Vet Sci 7:544594. https://www.frontiersin.org/article/https:// doi.org/10.3389/fvets.2020.544594

15. Nielsen El, Friberg LE (2013) Pharmacokinetic-pharmacodynamic modeling of antibacterial drugs. Pharmacol Rev 65:1053-1090. https://doi. org/10.1124/pr.111.005769

16. Toutain P-L, Bousquet-Melou A, Martinez M (2007) AUC/MIC: a PK/PD index for antibiotics with a time dimension or simply a dimensionless scoring factor? J Antimicrob Chemother 60:1185-1188. https://doi. org/10.1093/jac/dkm360

17. Toutain PL, Bousquet-Mélou A, Damborg P, Ferran AA, Mevius D, Pelligand L, Veldman KT, Lees P (2017) En Route towards European clinical breakpoints for veterinary antimicrobial susceptibility testing: a position paper explaining the VetCAST approach. Front Microbiol 8:2344. https:// doi.org/10.3389/fmicb.2017.02344

18. Schwarz S, Cavaco LM, Shen J, Aarestrup FM (2018) Antimicrobial resistance in bacteria from livestock and companion animals. First. ASM Press, Washington DC

19. European Medicines Agency (2015) New strategy to fight antimicrobial resistance. Eur Med Agency https://ema.europa.eu/en/news/new-strat egy-fight-antimicrobial-resistance. Accessed 18 Dec 2018

20. Muller AE, Theuretzbacher U, Mouton JW (2015) Use of old antibiotics now and in the future from a pharmacokinetic/pharmacodynamic perspective. Clin Microbiol Infect 21:881-885. https://doi.org/10.1016/j. cmi.2015.06.007

21. Riviere JE, Papich MG (2009) Veterinary pharmacology and therapeutics, $9^{\text {th }}$ edn. H. R. Adams IOWA-USA: Wiley-Blackwell

22. Lewicki J (2006) TYLOSIN, A review of pharmacokinetics, residues in food animals and analytical methods. http://fao.org/tempref/AG/agn/food/ tylosin_2006.pdf

23. Abu-basha EA, Al-shunnaq AF, Gehring R (2017) Comparative pharmacokinetics and bioavailability of two tylosin formulations in chickens after oral administration. J Hell Vet Med Soc. 63:159. https://doi.org/10.12681/ jhvms.15431

24. Kowalski C, Roliński Z, Zań R, Wawron W (2002) Pharmacokinetics of tylosin in broiler chickens. Pol J Vet Sci 5:127-130. http://europepmc.org/ abstract/MED/12448074
25. Paesen J, Cypers W, Pauwels K, Roets E, Hoogmartens J (1995) Study of the stability of tylosin A in aqueous solutions. J Pharm Biomed Anal 13:1153-1159. https://doi.org/10.1016/0731-7085(95)01522-M

26. Elazab ST, Elshater NS, Hashem YH, Park S-C, Hsu WH (2020) Pharmacokinetics, tissue residues, and ex vivo pharmacodynamics of tylosin against Mycoplasma anatis in ducks. J vet Pharmacol Therap 43:57-66. https:// doi.org/10.1111/jvp.12819

27. Abu-Basha EA, Gehring R, Hantash TM, Al-Shunnaq AF, Idkaidek NM (2009) Pharmacokinetics and bioavailability of sulfadiazine and trimethoprim following intravenous, intramuscular and oral administration in ostriches (Struthio camelus). J Vet Pharmacol Ther 32:258-263. https://doi. org/10.1111/j.1365-2885.2008.01036.x

28. Tulkens PM (1991) Intracellular distribution and activity of antibiotics. Eur J Clin Microbiol Infect Dis 10:100-106. https://doi.org/10.1007/BF019 64420

29. Toutain P-L, Bousquet-Mélou A (2004) Plasma clearance. J Vet Pharmacol Ther 27:415-425. https://doi.org/10.1111/j.1365-2885.2004.00605.x

30. Kim E-Y, Gebru E, Lee J-S, Kim J-C, Park S-C (2011) Pharmacokinetics of a florfenicol-tylosin combination after intravenous and intramuscular administration to beagle dogs. J Vet Med Sci 73:463-466. https://doi. org/10.1292/jvms.10-0243

31. Craig WA (1998) Pharmacokinetic/pharmacodynamic parameters: rationale for antibacterial dosing of mice and men. Clin Infect Dis 26:1-10. https://doi.org/10.1086/516284

32. Jacobs M, Grégoire N, Couet W, Bulitta JB (2016) Distinguishing antimicrobial models with different resistance mechanisms via population pharmacodynamic modeling. PLoS Comput Biol 12:e1004782. https:// doi.org/10.1371/journal.pcbi.1004782

33. Schentag JJ, Klugman KP, Yu VL, Adelman MH, Wilton GJ, Chiou CC, Patel M, Lavin B, Paladino JA (2007) Streptococcus pneumoniae bacteraemia: pharmacodynamic correlations with outcome and macrolide resistance-a controlled study. Int J Antimicrob Agents 30:264-269. https:// doi.org/10.1016/j.jiantimicag.2007.04.013

34. Vogelman B, Gudmundsson S, Leggett J, Turnidge J, Ebert S, Craig WA (1988) Correlation of antimicrobial pharmacokinetic parameters with therapeutic efficacy in an animal model. J Infect Dis 158:831-847. https:// doi.org/10.1093/infdis/158.4.831

35. Huang L, Zhang H, Li M, Ahmad I, Wang Y, Yuan Z (2018) Pharmacokinetic-pharmacodynamic modeling of tylosin against Streptococcus suis in pigs. BMC Vet Res 14:319. https://doi.org/10.1186/s12917-018-1645-3

36. Drusano GL, Fregeau C, Liu W, Brown DL, Louie A (2010) Impact of burden on granulocyte clearance of bacteria in a mouse thigh infection model. Antimicrob Agents Chemother 54:4368-4372. https://doi.org/10.1128/ AAC.00133-10

37. Toutain P-L, Pelligand L, Lees $P$, Bousquet-Mélou A, Ferran AA, Turnidge JD (2020) The pharmacokinetic/pharmacodynamic paradigm for antimicrobial drugs in veterinary medicine: recent advances and critical appraisal. J Vet Pharmacol Ther in press. https://doi.org/10.1111/jvp.12917

38. Lilia G, Aguilera R, Cortés-Cuevas A, Rosario C, Sumano H (2008) Circadian serum concentrations of tylosin in broilers after feed or water medication. Br Poult Sci 49:619-624. https://doi.org/10.1080/00071660802357033

39. Toutain P-L, Potter T, Pelligand L, Lacroix M, Illambas J, Lees P (2017) Standard PK/PD concepts can be applied to determine a dosage regimen for a macrolide: the case of tulathromycin in the calf. J Vet Pharmacol Ther 40:16-27. https://doi.org/10.1111/jvp.12333

40. Cao X-Y, Dong M, Shen J-Z, Wu B-B, Wu C-M, Du X-D, Wang Z, Qi Y-T, Li B (2006) Tilmicosin and tylosin have anti-inflammatory properties via modulation of COX-2 and iNOS gene expression and production of cytokines in LPS-induced macrophages and monocytes. Int J Antimicrob Agents 27:431-438. https://doi.org/10.1016/j.ijantimicag.2005.12.010

41. Nimmo WS, Peacock JE (1988) Effect of anaesthesia and surgery on pharmacokinetics and pharmacodyamics. Br Med Bull 44:286-301. https://doi. org/10.1093/oxfordjournals.bmb.a072252

\section{Publisher's Note}

Springer Nature remains neutral with regard to jurisdictional claims in published maps and institutional affiliations. 